\title{
قراءه سياسية
}

\section{في مبادرات اعلان الشرق الاوسط منطقة خالية من اسلحة الدمار الشامل}

(a)

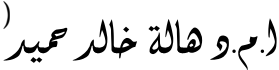

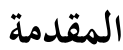

شهدت منطقة الشرق الاوسط مع بداية عقد التسعينات من القرن العشرين

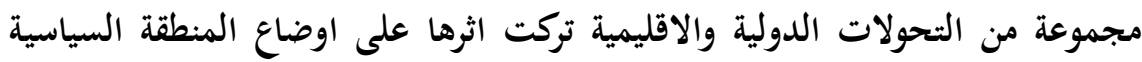

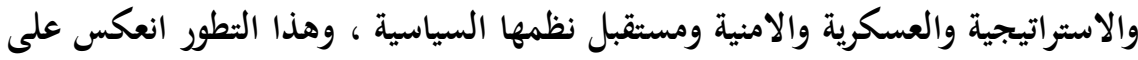
قضية ضبط التسلح في المنطقة ، فجعلت المطالبة بان تكون المنطقة خالية من اسلحة الدمار الشامل من القضايا المهمة والحيوية المؤثرة في مستقبل المنطقة متأثرة

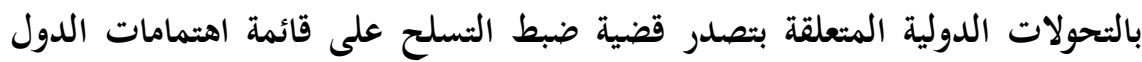
الكبرى ، حيث تم التوصل الى مجموعة من المعاهدات بدأت بالاتفاق الثنائي بين

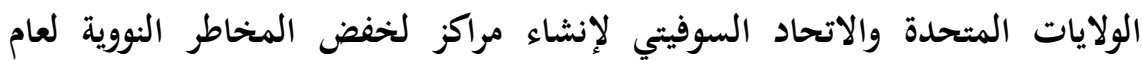
19AV

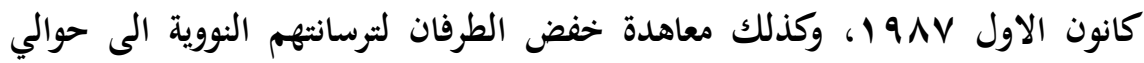
• • ب99 99 وهذا النطور على صعيد ضبط التسلح ادى الى ظهور مفاهيم جديدة كتدابير بناء الثقة والشفافية ، فضلا عن ذلك ان التغير الذي اصاب السياسات والترتيبات الامنية والاليات المستخدمة للحفاظ على المصالح الاستراتيجية للقوى الكبرى في المنطقة وخاصة الولايات المتحدة الامريكية التي اصبح ضبط انتشار اسلحة الدمار

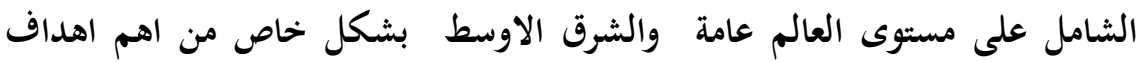

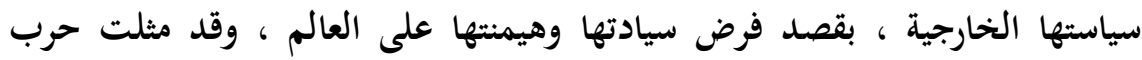
الخليج الثانية الفرصة الذهبية لإعادة ترتيب اوضاع المنطقة بما يخدم مصالحها 
الاستراتيجية والامنية ، بدءا بالقضاء على اسلحة الدمار الثامل العراقية ومرافق

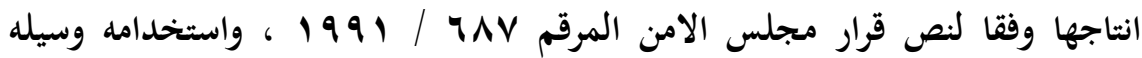
لتحذير دول المنطقة الاخرى من اية محاولة لتطوير قدراتها في هذا المجال ، وهذا الامر هو الذي ادى الى تطورات على المستوى الاقليمي ، حيث قاد الى زيادة الخلل في التوازن العسكري لصالح اسرائيل، والانفراد الامريكي في الترتيبات الامنية للمنطقة.

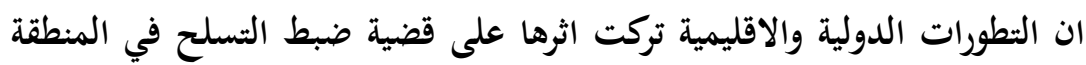
حيث قادت الى مبادرات عديدة دولية واقليمية وعربية وهذه المبادرات وخحاصة الدولية لن ينصب على اسلحة الدمار الشامل فقط ولا على منطقة الشرق الاوسط تحديدا مثل مبادرة الرئيس الامريكي جورج بوش ومبادرة الرئيس الفرنسي فرانسوا ميتران و ومبادرة

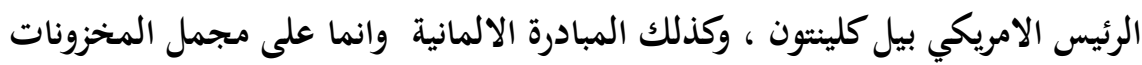

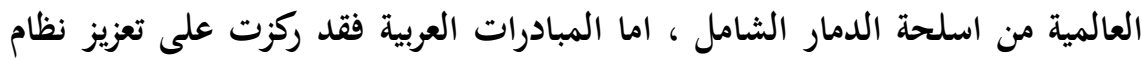

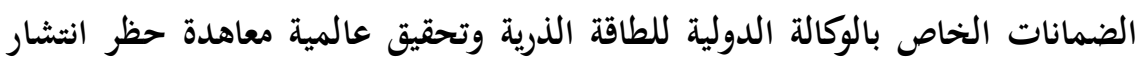

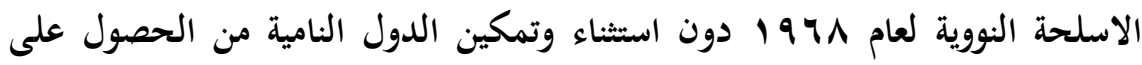
التقنية النووية للأغراض السلمية ـ وبناءا على ما تقدم ان جميع المبادرات الدولية

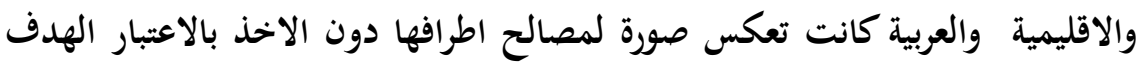

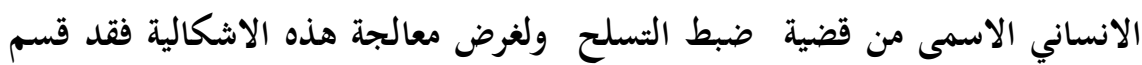

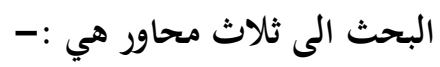

المحور الاول :- الاطار المفاهيمي للمنطقة الخالية من اسلحة الدمار الثامل .

$$
\begin{aligned}
& \text { المحور الثاني :- المبادرات الدولية. } \\
& \text { المحور الثالث :- المبادرات العربية . }
\end{aligned}
$$

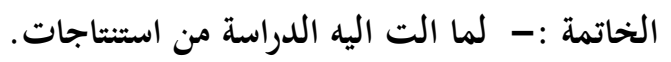


المحور الأول: اطار مفاهيمي

مفهوم المنطقة الخالية من الأسلحة النووية وأسلحة التدمير الشامل

برزت فكرة المناطق الخالية من الأسلحة النووية في نطاق العلاقات

الدولية بأعتبارها وسيلة لتأمين خلو بعض مناطق العالم من الأسلحة النووية وحظر إنتشارها ، ولعبت عوامل عديدة في في تطوير هذه الفكرة ، أولها : إدراك الدول فرادى لأعتبارات أمنها والظروف السائدة في منطقة معينة ، وثانياً : القلق الناتج في إحتمال حدوث هجوم نووي وخطر التورط في حرب نووية ، وثالثاً : الرغبة في

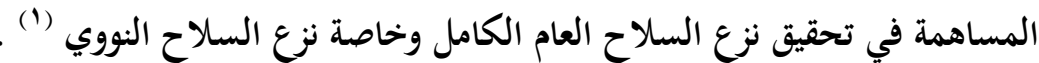
ويقصد بالمناطق الخالية من السلاح النووي "بأنها مناطق محظور فيها بموجب لمباح

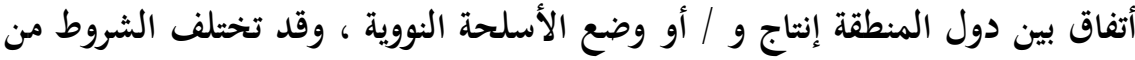

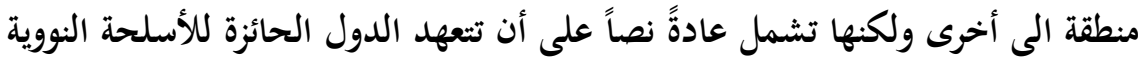

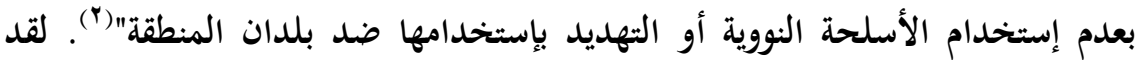
ظهرت هذه الفكرة في مفاوضات نزع السلاح في الأمم المتحدة وفي محافل دولية أخرى ذات علاقة، وقدمت عدد من الأقتراحات المتعلقة بالمناطق الخالية من الأسلحة

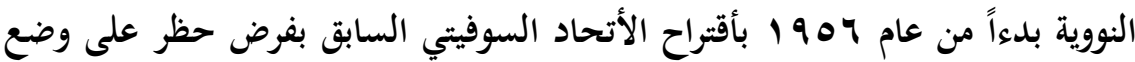
أسلحة نووية في أوروبا الوسطى ، ثم في عام 190V أقترحت بولندا إنشاء منطقة خالية من الأسلحة النووية في المنطقة نفسها، ثم توالت الأقتراحات الأخرى، حيث أقدام أقترحت رومانيا إنشاء منطقة سلام في البلقان، وفي عام 9909 أقترح الأتحاد السوفيتي إنشاء منطقة خالية من الأسلحة النووية في البلقان وبحر الأدرياتيكي ،ثم أتخذت الصين

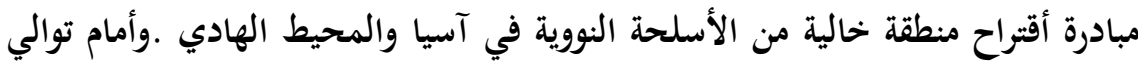
الأقتراحات الخاصة بأنشاء المناطق الخالية من الأسلحة النووية طلبت الجمعية العامة

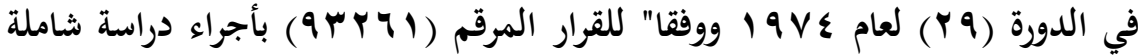
لمسألة المناطق الخالية من الأسلحة النووية من قبل فريق من الخبراء الحكوميين تحت

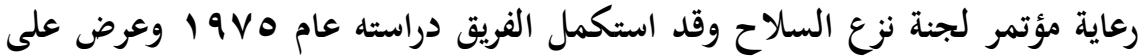


الجمعية العامة في دورتها الثلاثين .وتجدر الأشارة هنا الى أن هذه الدراسة والجهد تم

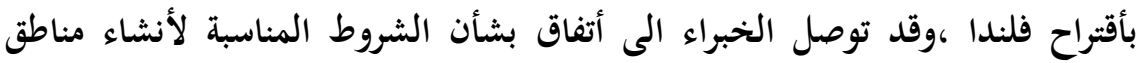

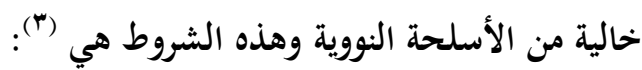

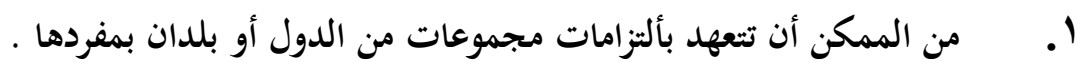

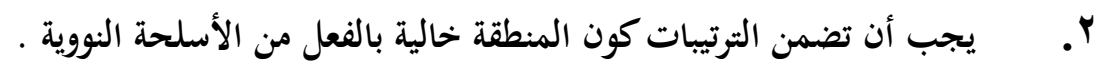

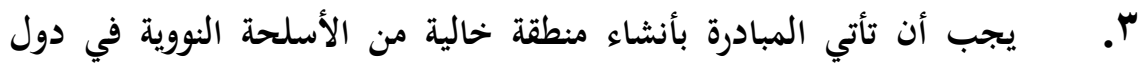

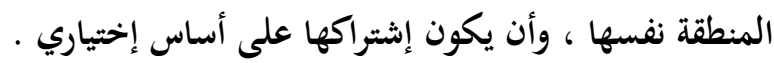

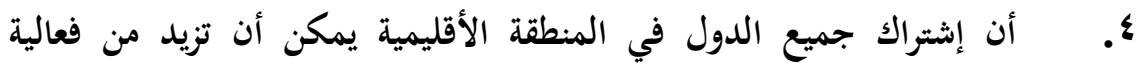
المنطقة الخالية من الأسلحة النووية .

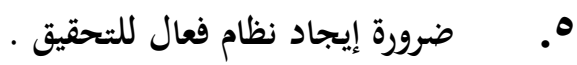

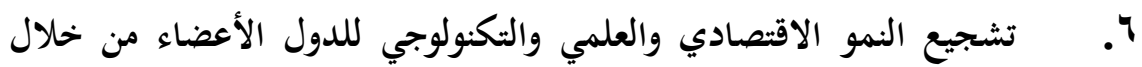
التعاون الدولي في مجال الأستخدامات السلمية للطاقة النووية . V. ينبغي أن تكون المعاهدة التي تنشأ بمقتضاها المنطقة الخالية من الأسلحة

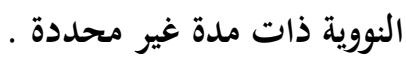
لقد دخل مفهوم المنطقة الخالية من السلاح النووي الى قاموس القانون الدولي ميلي

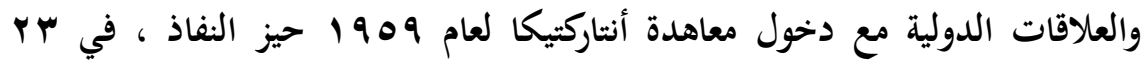
حزيران • 197 والخاصة بجعل المنطقة المتجمدة الجنوبية خالية من الأسلحة النووية

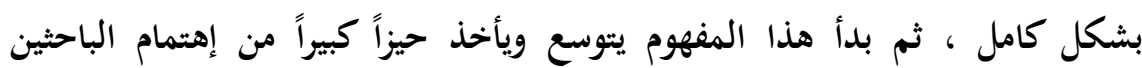

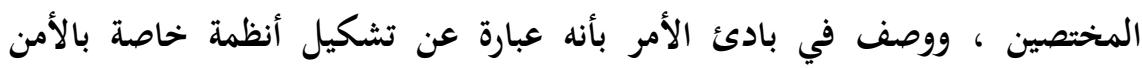

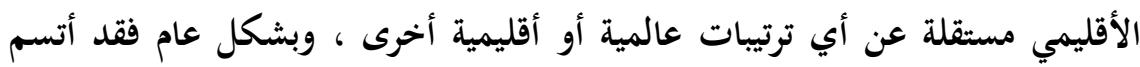

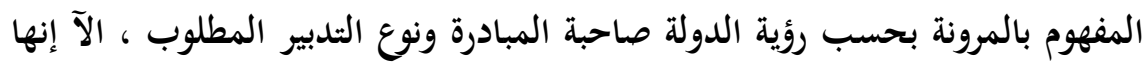

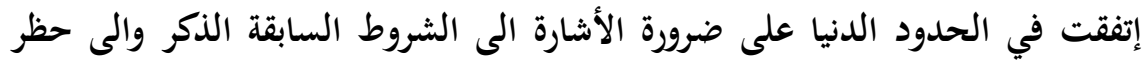

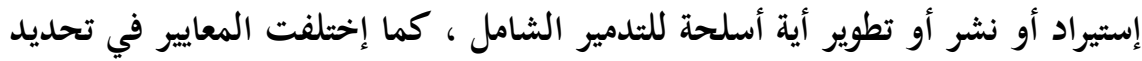

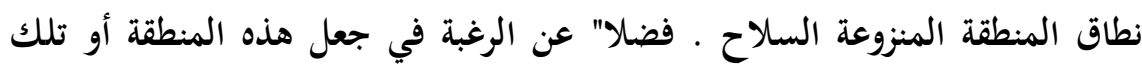

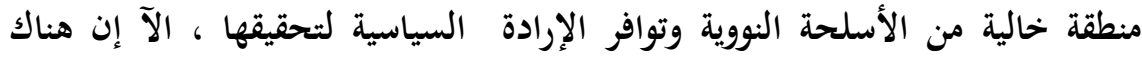


المعيار الجغرافي والأمني والثقافي ، ومن الأفضل أن يتوفر المعيار الجغرافي والأمني مع توفر عوامل تسهم في تشجيع نزع السلاح مثل الروابط الثقافية الايدلوجية

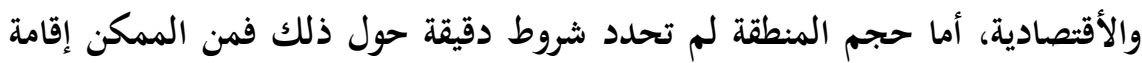
منطقة خالية محدودة ثم يتم توسيعها لاحقاً وهي تشمل فضلاً عن الأراضي، المياه

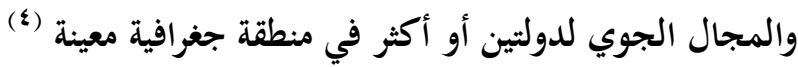
مفهوم منطقة الشرق الأوسط :

إن مصطلح الشرق الأوسط ذا أبعاد جغرافية وسياسية ، صعب تحديد نطاقه بصورة

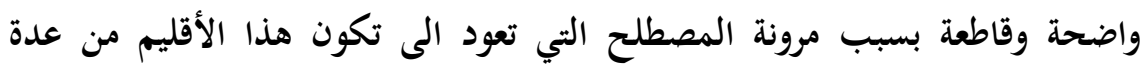

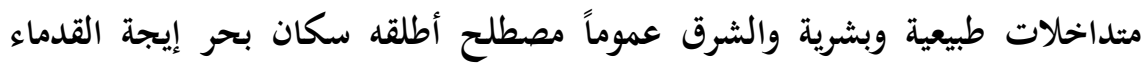

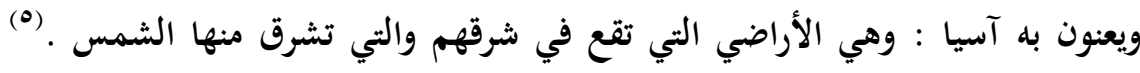
وأستخدم المصطلح لإول مرة بمفهومه الجيولوجي من قبل الديا (ألفريد ماهان) في مقال كتبه عام Y • 19 لمجلة ناشيونال ريفيو اللندنية بعنوان الخليج الفارسي والعلاقات

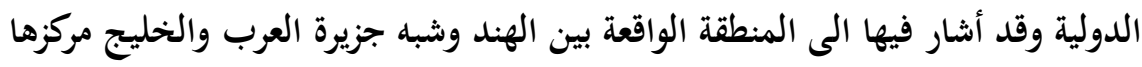

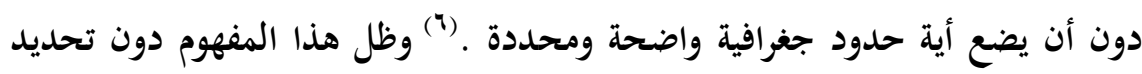

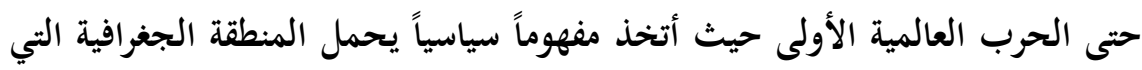

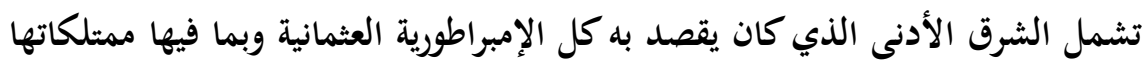

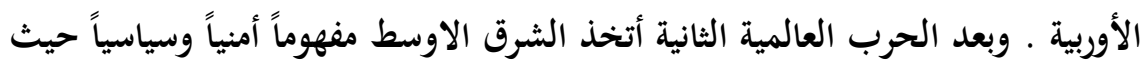
أستخدم الشرق الأوسط على أنه الإقليم الذي يشتمل على الدول الممتدة الديه من أيران

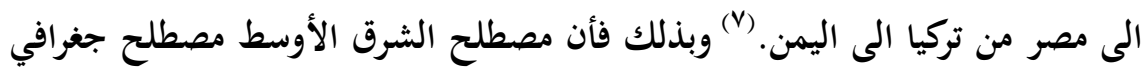

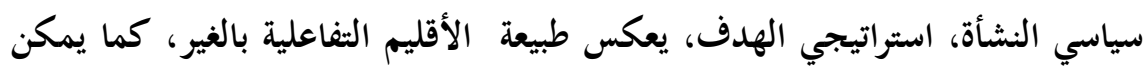

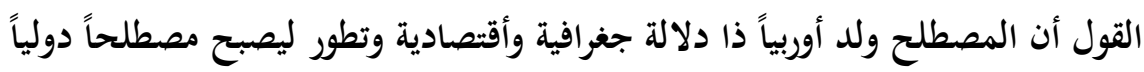
ذا دلالة سياسية واستراتيجية.

لقد طرأت على تفاعلات وتطورات وأهمية الشرق الأوسط تغيرات مهمة مع تغير

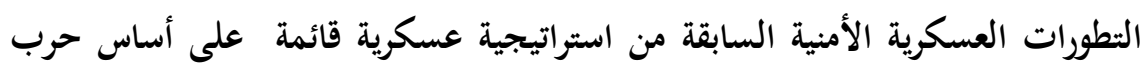


نووية شاملة بإتجاه التأكيد على القيمة العملياتية الفعلية لقوة التقليدية ، مع الاحتفاظ بدرجة عالية من المصداقية جنباً الى جنب مع القوات النووية ، والذي يعني إعادة توزيع

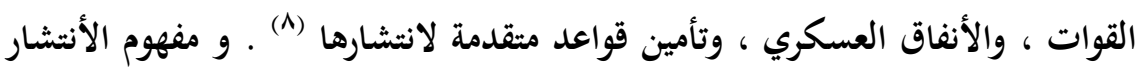

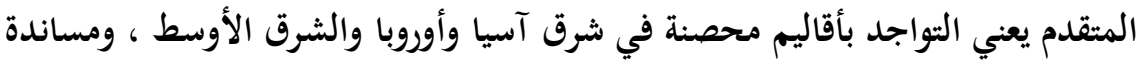

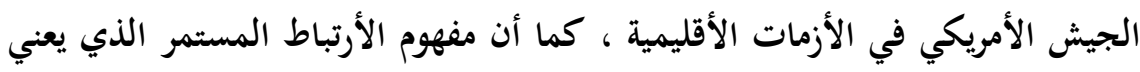

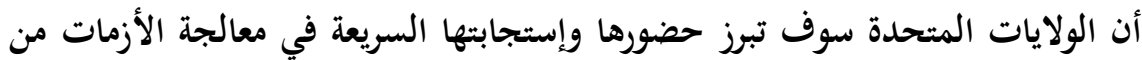

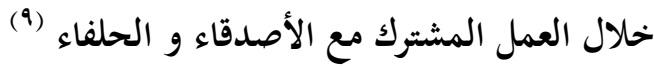
وهذا الواقع الاستراتيجي الجديد مع عدم القدرة على تحديد الأطار الجغرافي للمنطقة بسبب إختلاف المعايير المستخدمة أو لإختلاف غايات وأهداف ومصالح كل طرف لهد من هذا التحديد ، ترك أثره على قضية نزع السلاح وإنشاء منطقة خحالية من الأسلحة

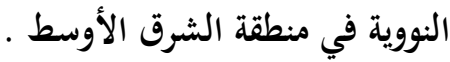

حيث برزت قضية تحديد النطاق الجغرافي للمنطقة باعتبارها من القضايا المهمة

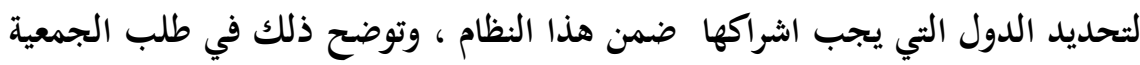

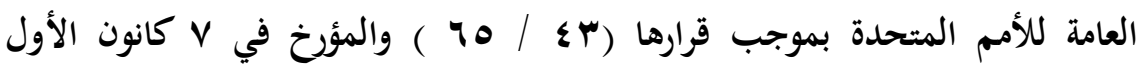
1911 ، ، الى الأمين العام بدراسة التدابير الفعالة التي يمكن التحقق منها والكفيلة بتيسير إنشاء هذه المنطقة ، وجاءت الدراسة لتؤكد صعوبة تحديد ومناقشة حدود الشرق الأوسط ، وبما أن هذا الأمر ضروري لتحديد الدول التي يجب إشراكها ضمن هذا النظام ، فقد إقترحت الدراسة تقسيم دول المنطقة الى بلدان أساسية وأخرى

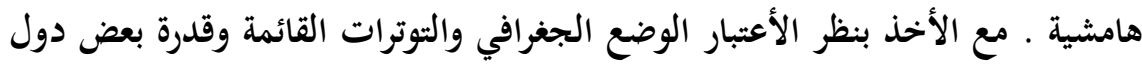

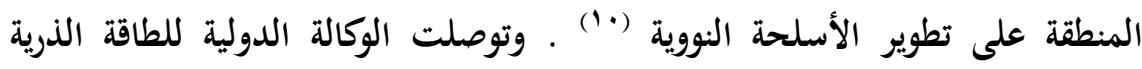

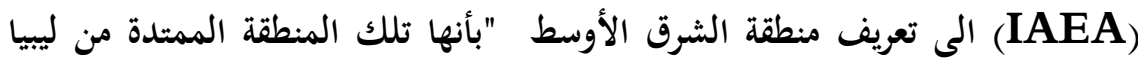

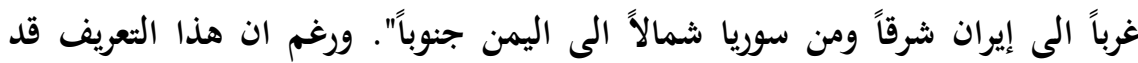

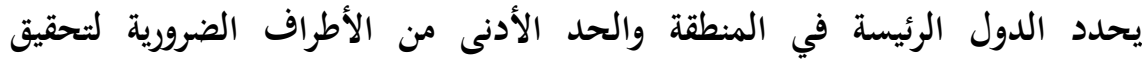
المشروع، الآ إنه جاء قاصراً لأنه يحدد مهمتها ولذلك إقترحت ضم لمد جميع الدول

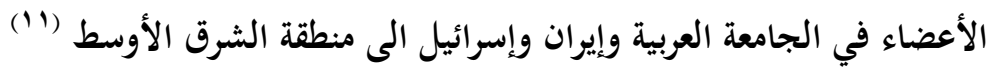


وعلى الرغم من أن مبادرات ومقترحات إخلاء الشرق الأوسط من الأسلحة النووية

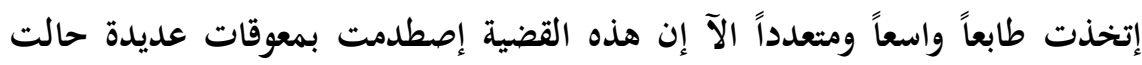
دون تنفيذ أو تطبيق هذه المبادرات سواء كانت الاقليمية والدولية. بعض هذه

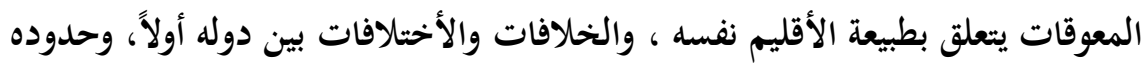

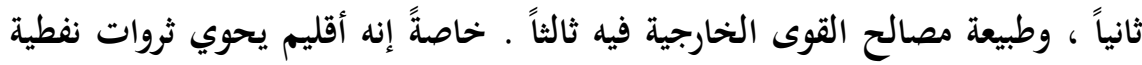
ومعدنية وبشرية كبيرة ، فضلاً عن موقعه الجغرافي بالنسبة الى آسيا واوربا .

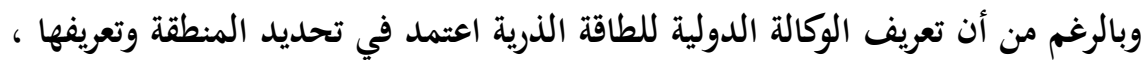

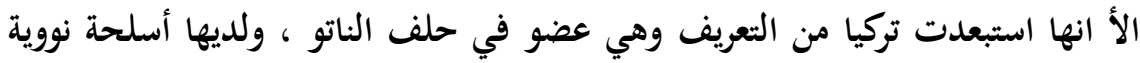

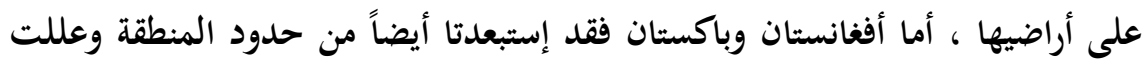
ذلك في أن إهتماماتها السياسية والعسكرية تتركز في إتجاهات أخرى، وهناك اسباب

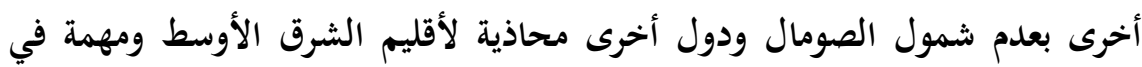

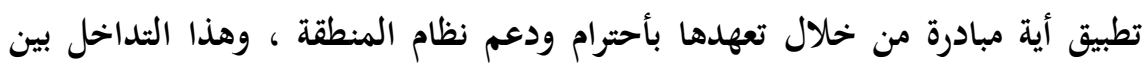

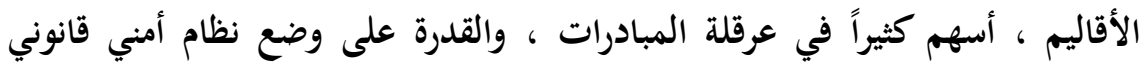

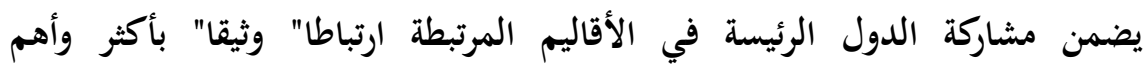
الصراعات والثفاعلات في المنطقة . إن منطقة الشرق الأوسط حظيت بفرص كثيرة لتحقيق منطقة خالية من الأسلحة النووية ، كونها جاءت متطابقة مع الأسس والمبادئ التي ينبغي تواجدها عند إقامة المنطقة

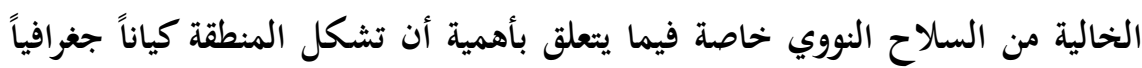

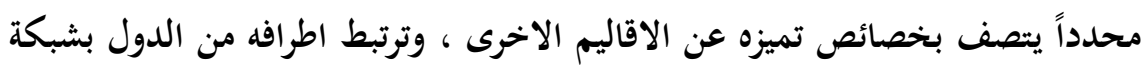

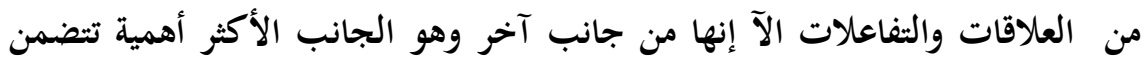
نقاط ضعف شكلت معوقات أمام تشكيل المنطقة منها :

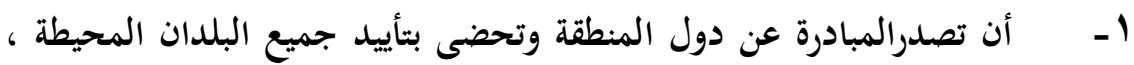

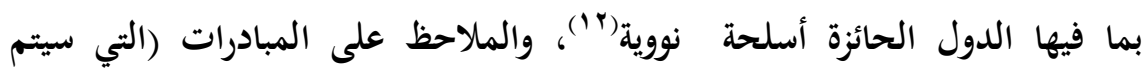
ذكرها) إنها جاءت نتيجة تزايد الأنفاق العسكري وسباق التسلح، خاصة مع اعلان قيام الكيان الصهيوني في فلسطين عام \ـ 9 1 ، وإعتبار الخيار النووي خيارا" استراتيجيا" 
رادعاً هذا الكيان ، حيث أصبح السلاح النووي جزء من العقيدة العسكرية الصهيونية وفقاً لمبدأ ( بن غوريون ) بما يسمى بالردع التصاعدي الذي يعني زيادة القدرة الثدميرية

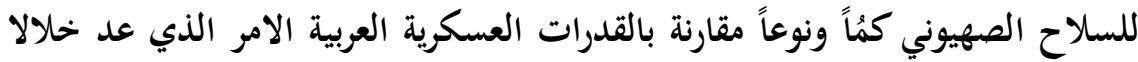

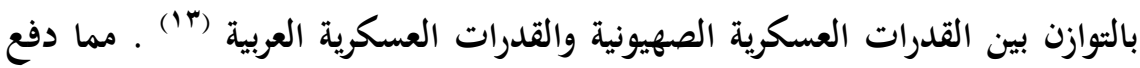
بعض دول الثرق الأوسط ومنها بعض الدول العربية بأمتلاك بنى تحتية لبرامج نووية ، وإمتلاك مفاعلات نووية بهدف تحقيق نوع من التوازن بين الطرفين ، وفي ظل تصاعد الصراع العربي - الصهيوني ، وتدخل قوى خارجية في هذا الصراع وإدراج القضايا

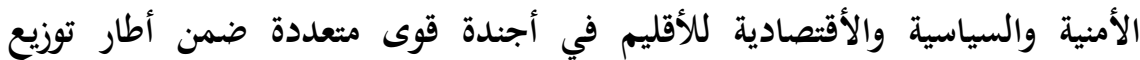
الصفقات والغنائم ، فإن عملية إيجاد مبادرة داخلية ذاتية تنبع من الحاجة الحقيقية لنزع السلاح ودون تدخل القوى خارجية ، يعد أمر بعيد المنال خاصة مع التطورات التي أصابت المنطقة بعد عام • 199 ، وسعي الولايات المتحدة الى إعادة ترتيب الأوراق في منطقة الثرق الأوسط وفق مصالحها الاستراتيجية والامنية . Y - تحديد النظام الأساسي الذي ستخضع له المنطقة فيما يتعلق بالأنعدام التام

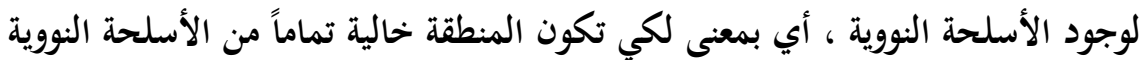

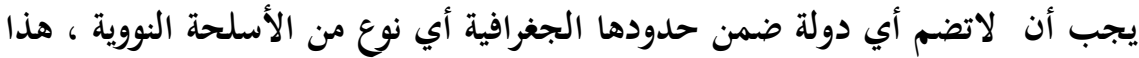

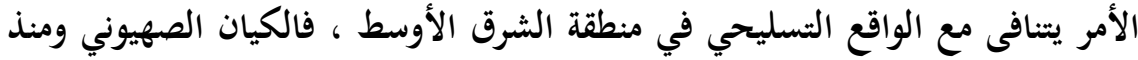

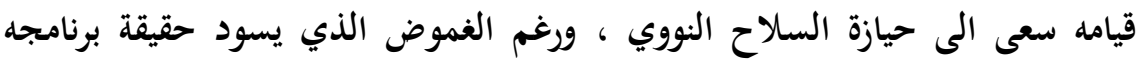

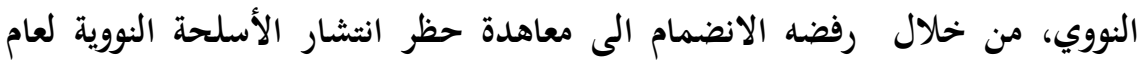
19 194، وعدم إخضاع منشآته النووية للمراقبة والمفتشين بموجب بروتوكول الضمانات

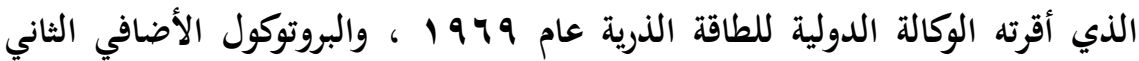

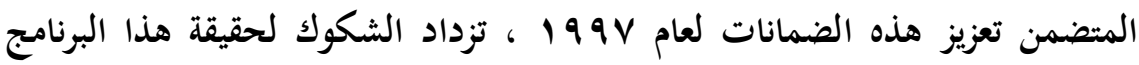

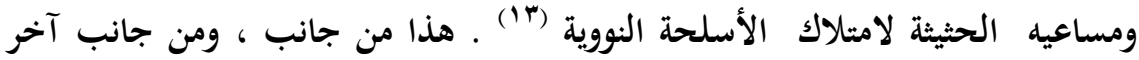
فإن النشاطات النووية التي بدأت في أواخر الثمانينات وأوائل التسعينات من القرات

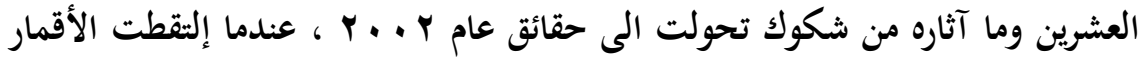
الصناعية صور لمنشآت نووية إيرانية تحت الأنشاء وغير معلن عنها ، دفعت بالوكالة 
الدولية للطاقة الذرية التحقيق حول البرنامج النووي الأيراني وكانت نتيجة التحقيقات تشير الى أن إيران تسعى لتخصيب اليورانيوم ( إنتاج الوقود النووي ) وفصلت

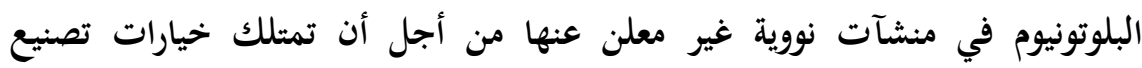

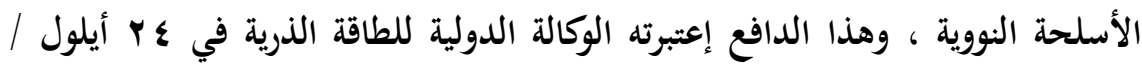

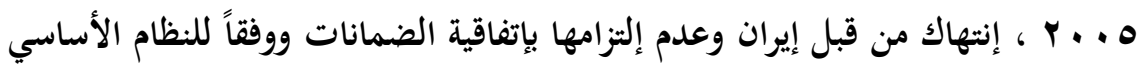

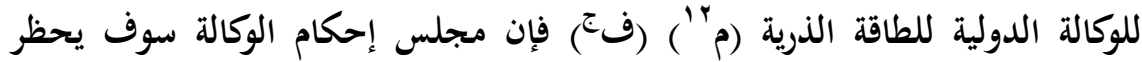

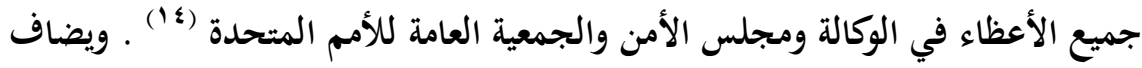

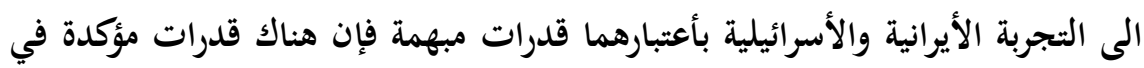

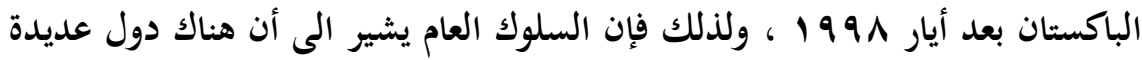

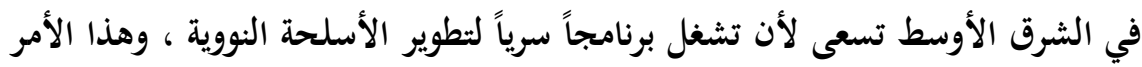

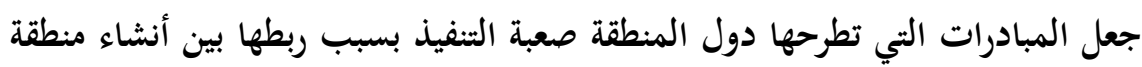
منزوعة السلاح والتخلي عن البرامج النووية وإن كانت مخصصة لإنتاج الوقود النووي

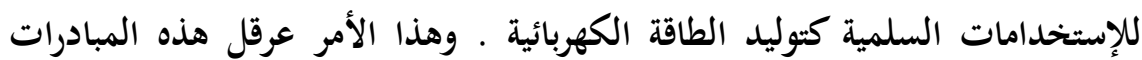
بسبب رفض هذه الدول للإجراءات التحقيقية المطلوبة . r ـ أن تتفق أحكام المنطقة الخالية من الأسلحة النووية مع مبادئ وقواعد القانون

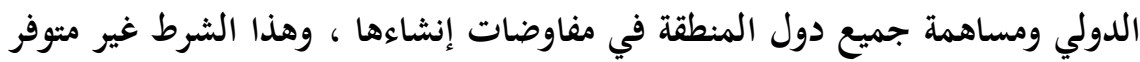
في منطقة الشرط الأوسط، نظرا" للاختلاف على حدودها وماهية الدول المنظمة اليها، فهناك خحلافات وصراعات سياسية وعسكرية بين دوله ، وهناك صراعات مستمرة مثل

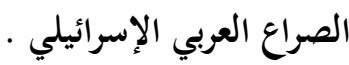
إن ما تقدم لم يمنع دون تقديم مبادرات أقليمية ودولية لإنشاء منطقة خحالية من السلاح وبقصد تحقيق الأمن والأستقرار الأقليمي من خحلال ربط دول المنطقة في أطار ترتيبات أمنية تتعلق بتنظيم العلاقات السياسية والأقتصادية والعسكرية فيما بينها ، والدول لدول

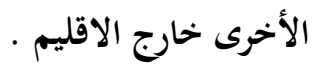


المحور الثاني : المبادرات الدولية لجعل الشرق الأوسط منطقة خالية من الأسلحة

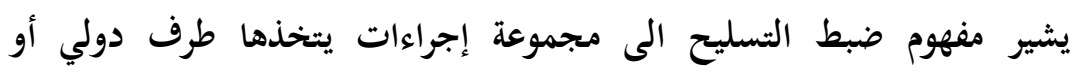

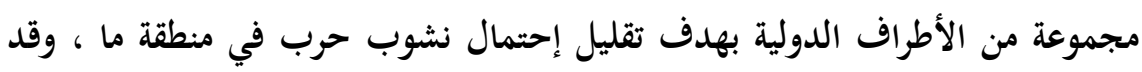

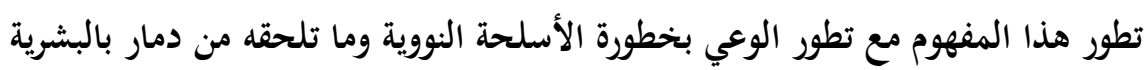

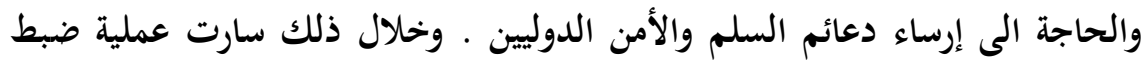

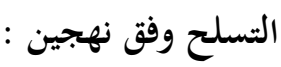

الأول :- هو نهج حظر الانتشار الشامل والنهج الشامل الذي قاد الى ابرام معاهدة

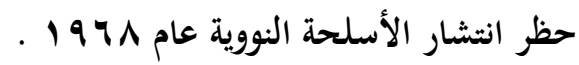
الثاني :- نهج إقليمي متعلق بمبدئ قضية ذات شروط معينة تنطبق عليها شروط الام الدئ

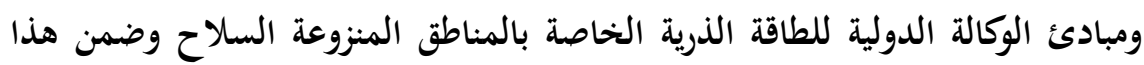
النهج أبرمت معاهدات عده هي (10) :

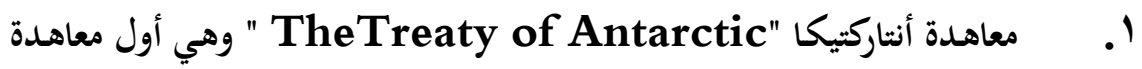
تعلن وتعترف بانشاء بأول منطقة خالية من الأسلحة النووية فتحت للتوقيع في اكانون

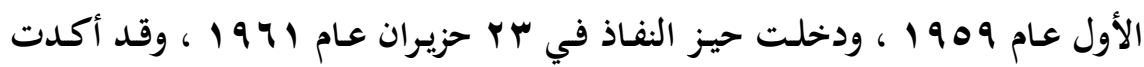

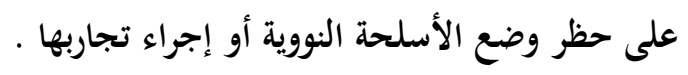

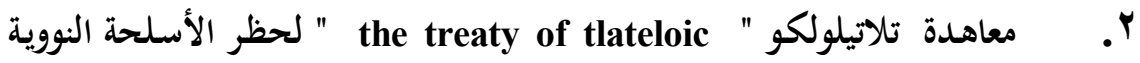

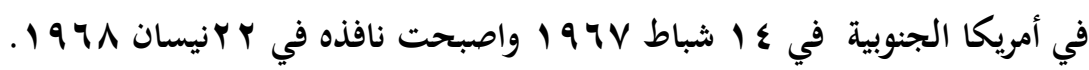

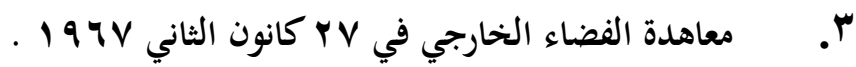

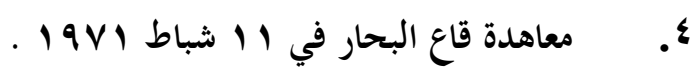

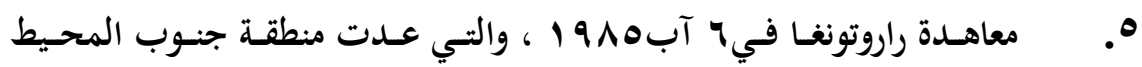
الهادئ منطقة خالية من الأسلحة النووية . 
צ. معاهدة بانكوك " the treaty of Bangkok في 1990/1 19/10، لجعل منطقة جنوب آسيا خالية من الأسلحة النووية واصبحت نافذة المفعول في VV اذار

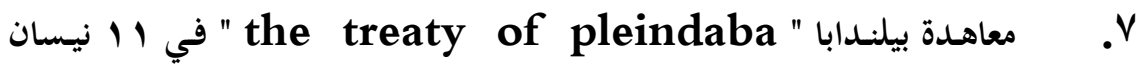
ج99 99 لإنشاء منطقة خالية من الأسلحة النووية في أفريقيا .

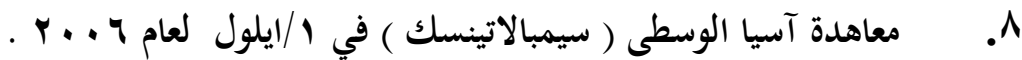

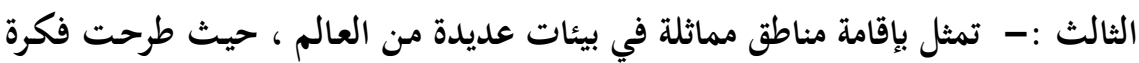
جديـدة في عـام بـ919، بإقامـة ممـر في وسط أوروبـا تسحب منسه الأسلحة النوويـة بنوعيها التكتيكي والأستراتيجي ، لتقليل خطر استخدام هذا النوع من الأسلحة ، ولم يتصل نطاق التطبيق بالحدود الوطنية للدول المعنية ولم تطبق أي ضمانات أمنية ولذلك لم تجري بشأنه أي مفاوضات بسبب وجود خحلافات جوهرية حول النهج الذي تبعته

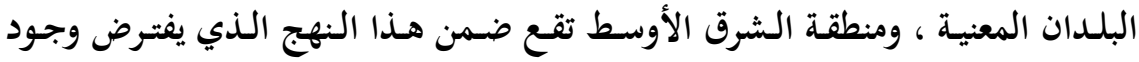

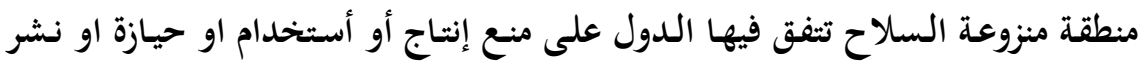

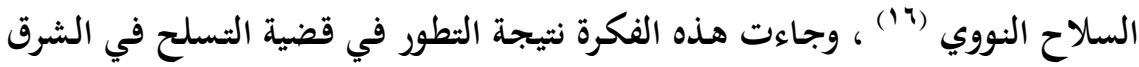

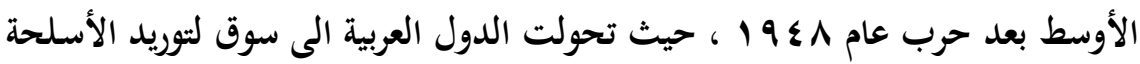
ومن مختلف الأنواع ، وبقيت حالة سباق التسلح في المنطقة في تسارع في المنطقة وفي المقابل كانت هناك جهود دولية في مجال خفض التسلح فيها ، وكانت معظمها

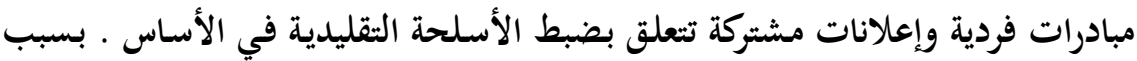

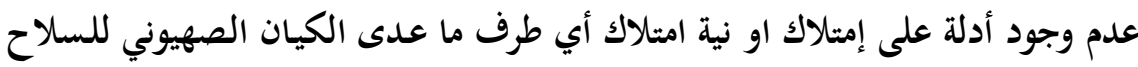

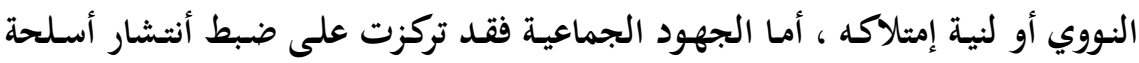

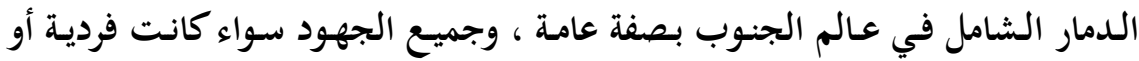

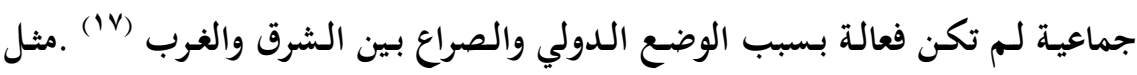

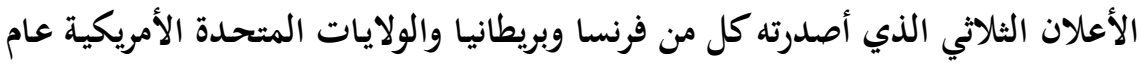
• 190 ، تعهدت بموجبه بفرض قيود على تصدير الأسلحة لدول المنطقة بما لايخل

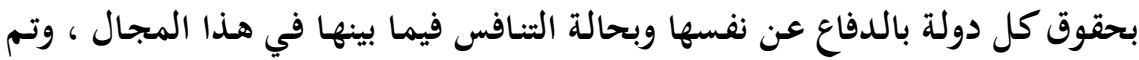


إنشاء " لجنة الشرق الأدنى لتنسيق التسلح " لمراقبة الصادرات ، وقد خرقت فرنسا

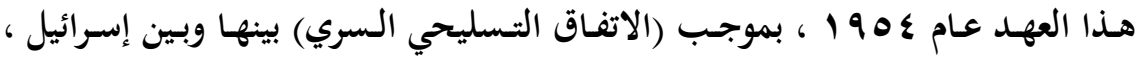

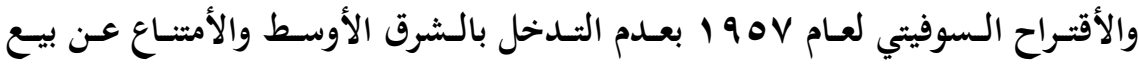
الأسلحة لدولها وقد رفضت الولايات المتحدة الأمريكية هذا المقترح وأعتبرته محاولة لتحجيم النفوذ الغربي في المنطقة من خلال السيطرة على أهم مجال في نفوذها وهو

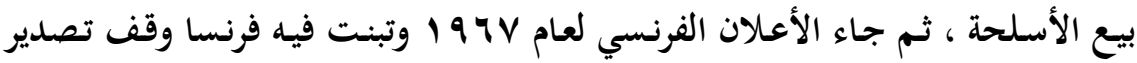

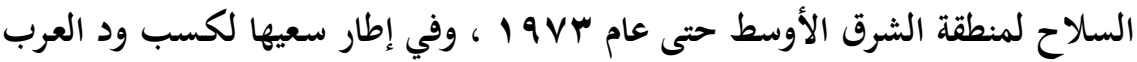

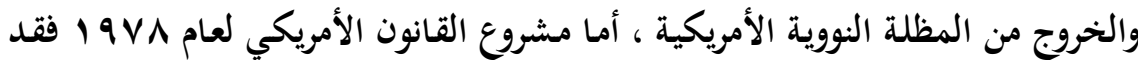
جاء محاولة للتغلب على الخوف من أنتشار التقنية النووية بين دول العالم الثالث ، فـأعلن الرئيس الأمريكي الأسبق (جيمسي كـارتر ) بتوقـف جميـع صـادرات الولايسات المتحدة النووية لأي دولة غير نووية لاتخضع نشاطاتها النووية لإجراءات ضسمانات في لهي

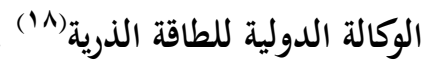
وبعـد نهايـة الحرب الباردة حـدثت تطورات سياسية غيـرت ملامـح الشرق الأوسط ،

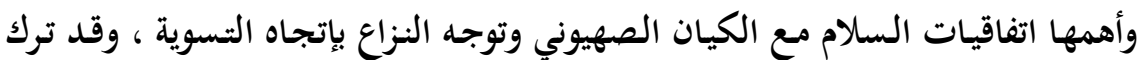

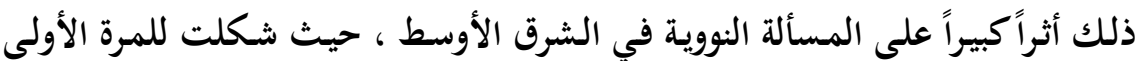
بعد مؤتمر مدريد للسلام مجموعة عمل متعـددة الأطراف للبحث في ضبط التسل التسلح والأمن الأقليمي ووضعت في جددول أعمالها مشروع إنشاء منطقة خحالية من أسلحة اللدمار الشامل ، وهـذا التوجـه يـشير الى أن السلام وحظر الأنــشار النووي أصسبحا

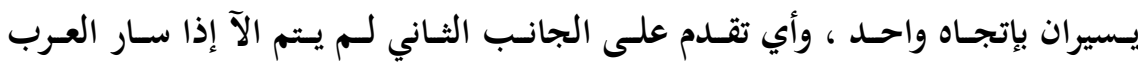

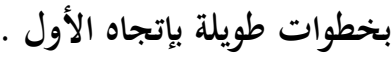
أما العراق وإيران فإن العقوبات الأقتصادية على العراق في بداية التسعينات وتدمير

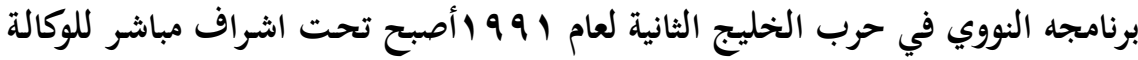

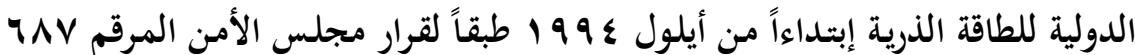
العـام ال199 ، والقرارات ذات الصلة، وقـد أدى ذلك الى أن تشهـد منطقة الشرق الأوسط مـع بدايـة التسعينات مجموعـة من التحولات جعلدت من قضية إنشاء منطقة 
خالية من اسلحة الدمار الشامل من القضايا الحيوية المؤثرة في مستقبل النظام الأقليمي

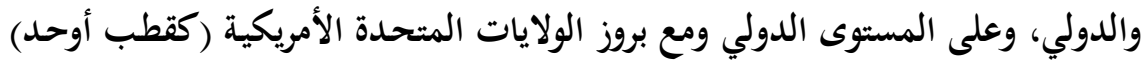

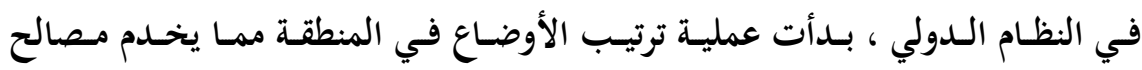

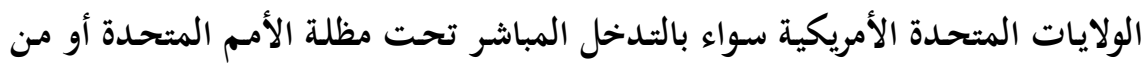
خلال فرض السلام الذي يضمن تحقيق التوازن بين تأمين الأمدادات النفطية من جهة والحفــاظ على علاقـات الـصداقة مـع دول الخلـيج ، وبــين إسـتمرار الـدعم الكامـل

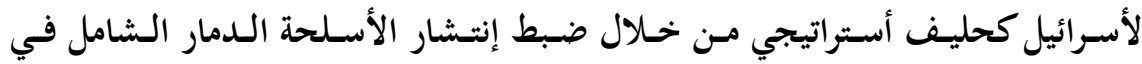

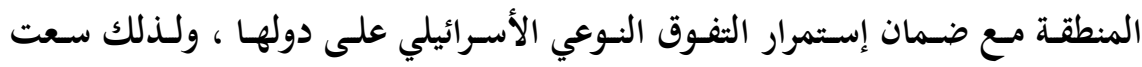

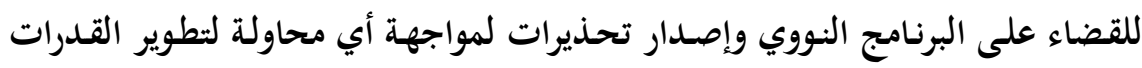

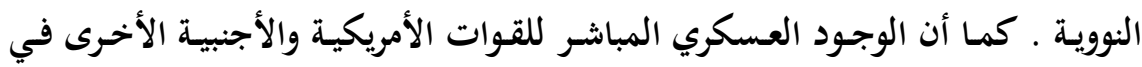
المنطقة جعل القرار السياسي والأرادة السياسية لدولها مرتبطة إرتباطا" كبيرا" بالقرار السياسي الأمريكي ومصالحه في المنطقة مما أفرغ مفهوم منطقة منزوعة السلاح من ونس

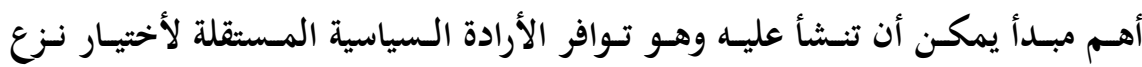

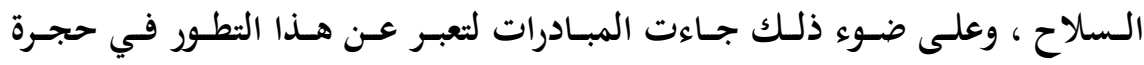

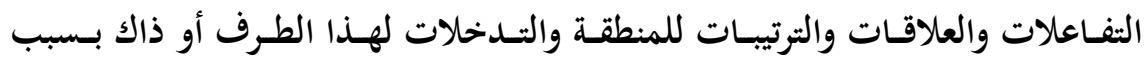
أختلاف وتقاطع المصالح في منطقة تزخر بثروات وفيرة مثل الشرق الأوسط ويمكن تحديد أهمها : تحسنات

$$
\text { أولاً : المبادرات الأمريكية : :- المبهات }
$$

أ- مبادرة جورج بوش لضبط التسلح في الشرق الأوسط :

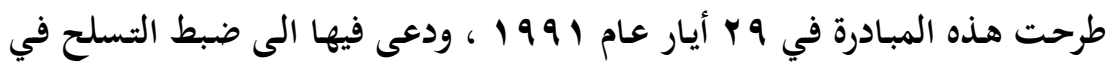

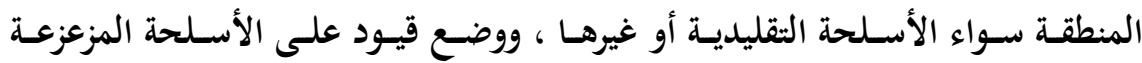

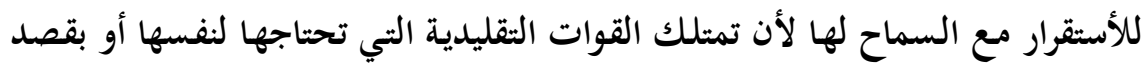

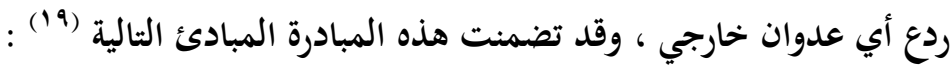




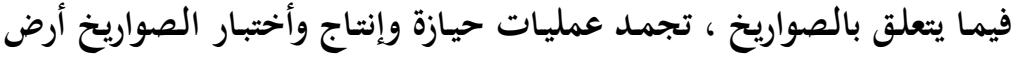

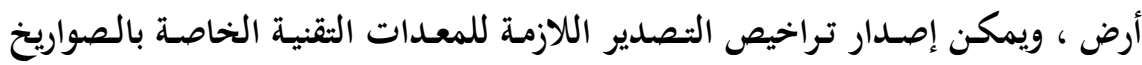

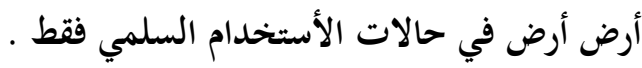

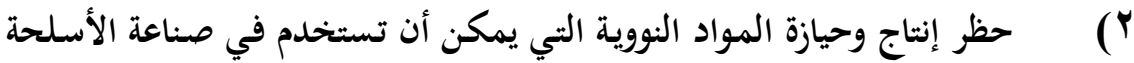
النووية وتشمل " البلوتونيوم واليورانيوم المخصب ووسائل إيصالها " .

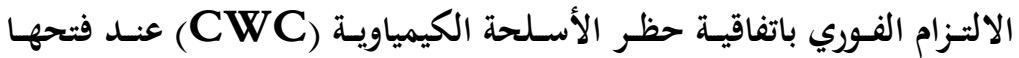
للتوقيع في || - 1 ا كانون الثاني ب99 9 اوتدعيم معاهـدة حظر الأسلحة البايولوجية لعام Y I I من خلال تطبيقها . تضمنت المبـادرة بنـداً يتعلق بـالظوابط المقترحسة والخاصـة بتصدير الأسلحة ( التقليدية ، حيـث دعت الدول الخمس الدائمة في مجلس الأمن المجهزة للأسلحة

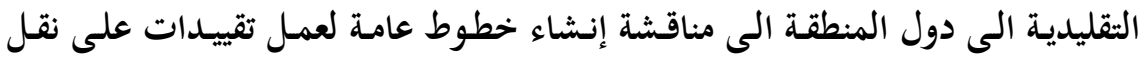
الأسلحة الثقليدية وما يرتبط بها من أسلحة الدمار الشامل .

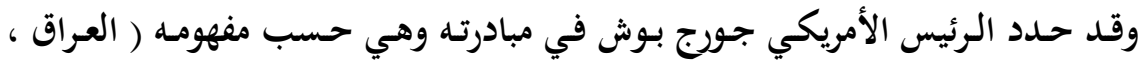

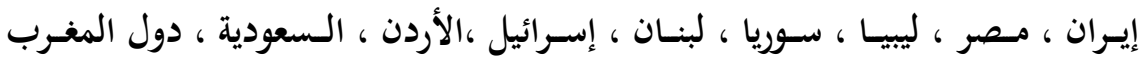

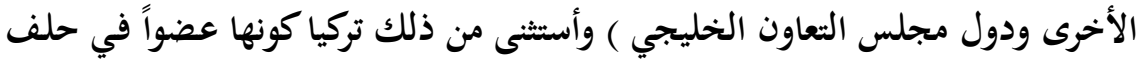

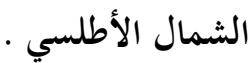
ولكي يـتم وضـع هـــه الضوابط موضـع التنفيـذ فقـد الزمــت المبـادرة الـدول الخمـس

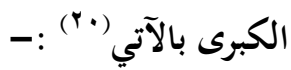
الحد من مبيعات السلاح لاسيما مبيعات صواريخ أرض أرض والتقنية المتعلقة بها ب- وضع نظام لتبادل المعلومات عن مبيعات السلاح المبرمة مع دول المنطقة وتوزيع تقرير سنوي عن مبيعاته من السلاح للشرق الأوسط .

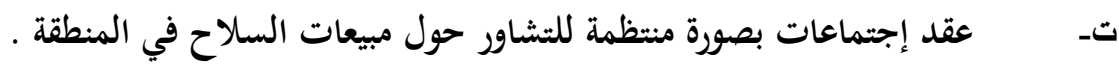
لقد أغفلت المبادرة التسلح الأسرائيلي وتعاملت مع الدول الأخرى بإزدواجية واضحة فسعت المبادرة نحو وضع حظر وقيود على جميع عمليات إنتاج وحيازة المواد النووية 


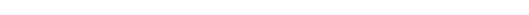

وأكدت على ضرورة التزام الدول الأطراف في معاهدة حظر الأنتشار ، وإتفاقيتي حظر

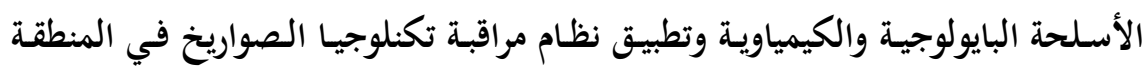

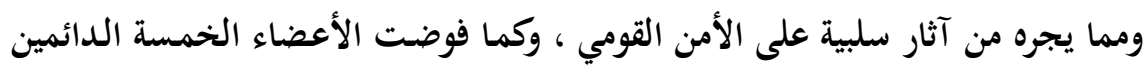

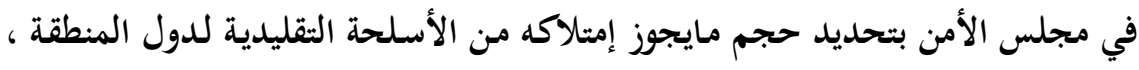

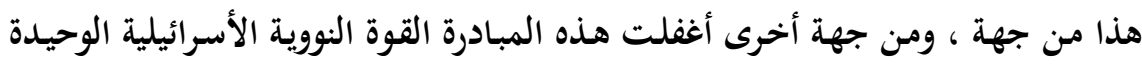

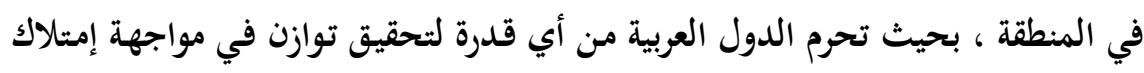

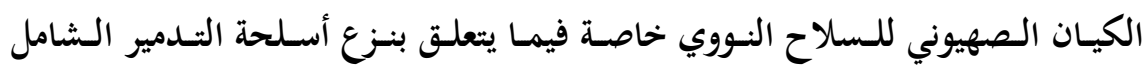

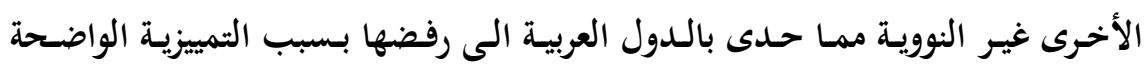

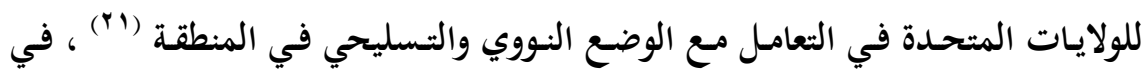

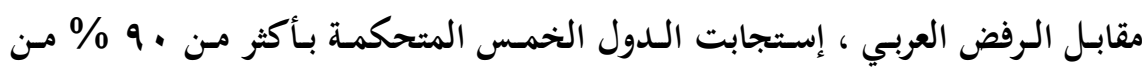

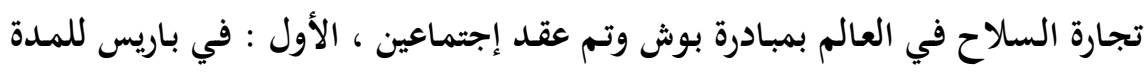

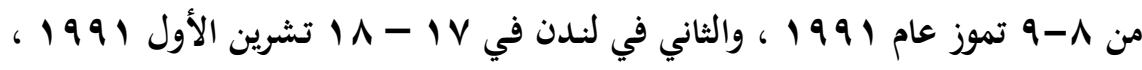

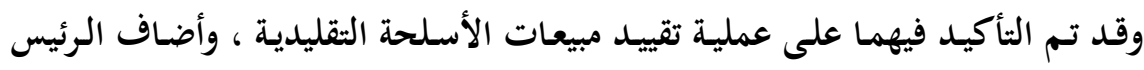

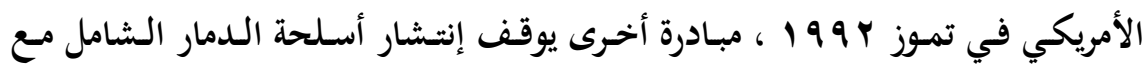

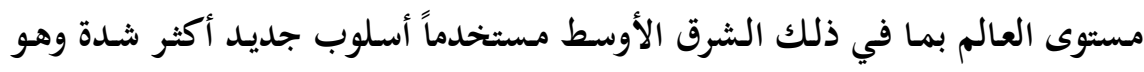

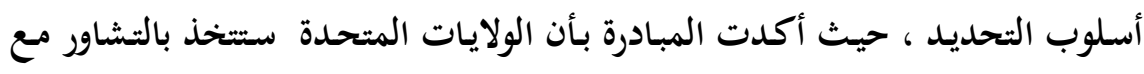

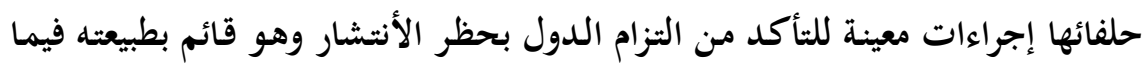

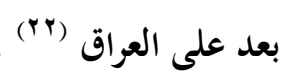
على الرغم من تأييد الدول الخمس المبادرة الآ إن خلافات عديدة قادت الى توقفها

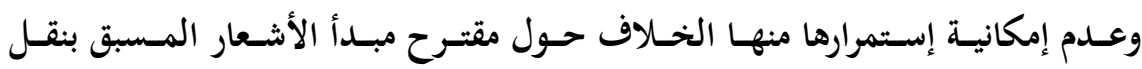

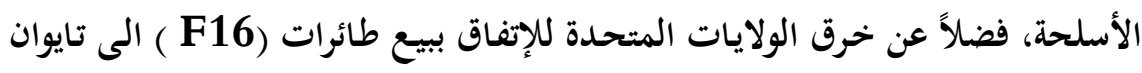

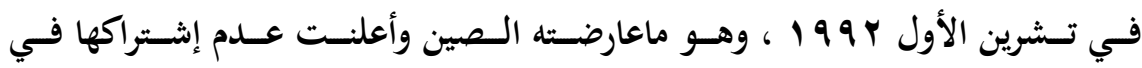

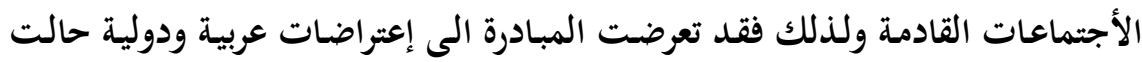

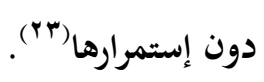




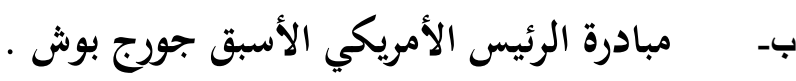

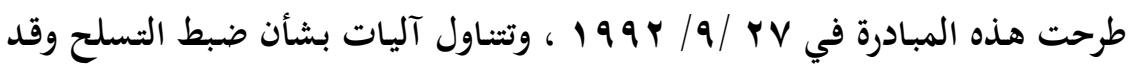

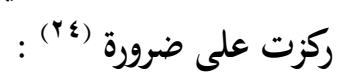

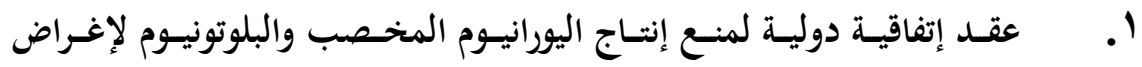

التفجير مع وضع حد وضوابط لإستخدام البلوتونيوم في البرامج السلمية .

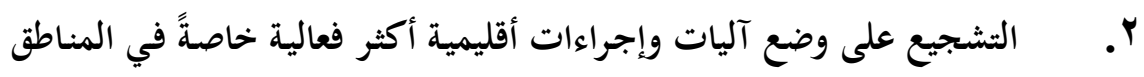

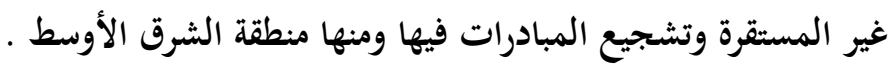

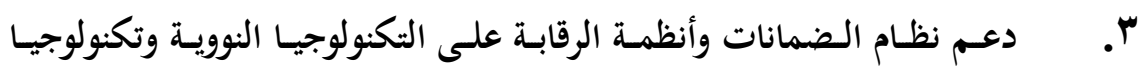
الصواريخ

؛. تشجيع العمل بإتجاه خلق وإنشاء مناطق خالية من أسلحة التدمير الشامل .

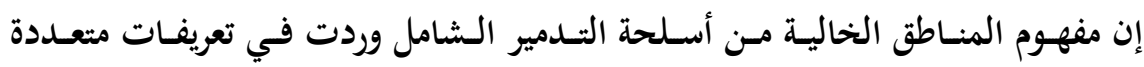

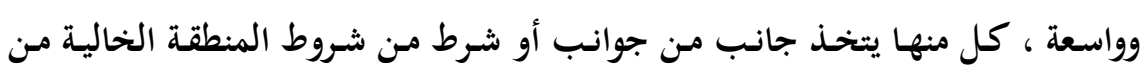

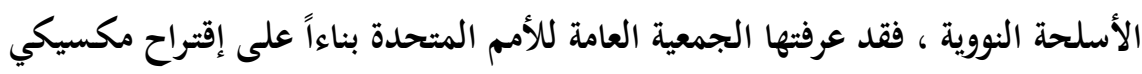

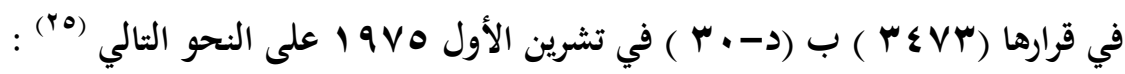
أولاً : من حيث المفهوم :

l. هي أي منطقة تعترف بصفتها هذه الجمعية العامة للأمم المتحدة وتنشأها أي

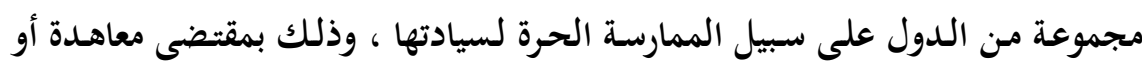

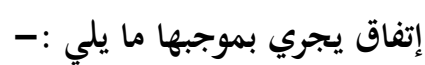

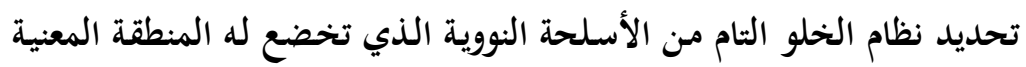
بما في ذلك الأجراء الخاص بتعيين حدود المنطقة . إنشاء جهاز دولي للتحقق والمراقبة لضمان الأمتثال للإلكزامات الناشئة عن التحن ذلك النظام 
Y- تعريـف الالتزامـات الئيسـة بالنسبة للـدول الحسائزة للأسـلحة النوويـة تجـاه هـــه

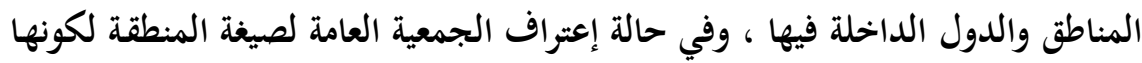
منطقة خالية من الأسلحة النووية .

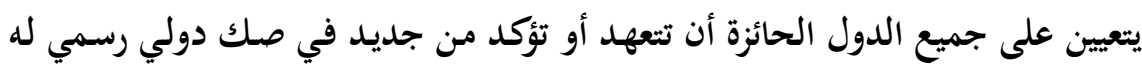
قوة الألزام القانوني الكامل كمعاهدة أو إتفاقية أو بروتوكول بالألتزامات الآتية :

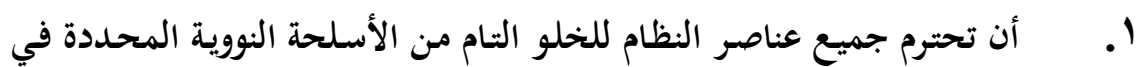
المعاهدة أو الأتفاقية المنشئة للمنطقة .

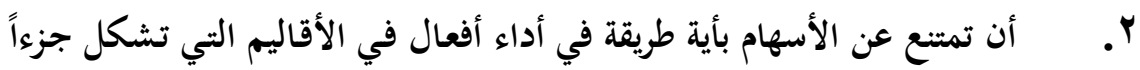
من المنطقة تكون منطوية على إنتهاك المعاهدة أو البروتوكول المذكور.

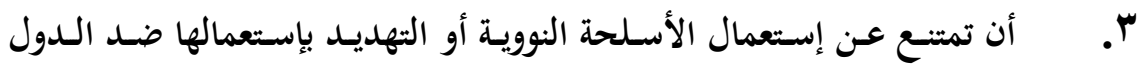

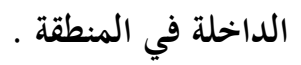
وقد أعتمدت معظم الأدبيات والتعريفات اللاحقة للمناطق الخالية من الأسلحة

$$
\begin{aligned}
& \text { النووية ، هذا التعريف كتعريف أساسي أو ضمني لها ـ اله }
\end{aligned}
$$

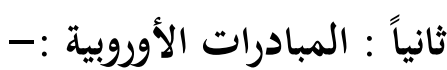

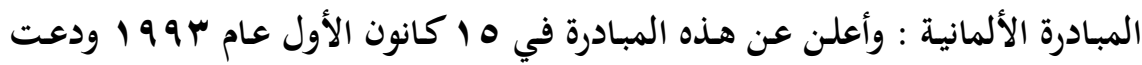

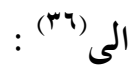

إنشاء نظام دولي للسيطرة على البلوتونيوم .

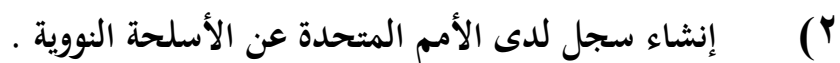

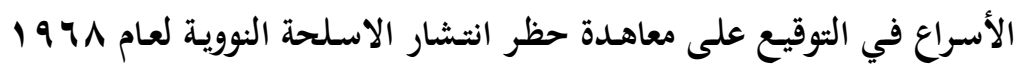

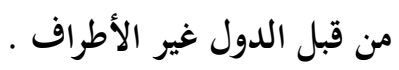

السعي لأقامة مؤتمر دولي لسد الثغرات الموجودة في معاهدة حظر الأسلحة

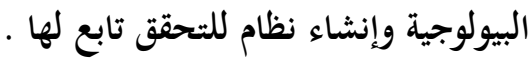

تطوير نموذج مؤتمر الأمن والتعاون الأوروبي كنموذج لسياسة عدمد الأنتشار 
年

تكثيـف الجهـود لأبـرام معاهــدة دوليـة للحظر الـشامل للتجـارب النوويـــ

$$
\begin{aligned}
& \text { تشديد الرقابة على تجارة المواد النووية . } \\
& \text { مبادرة الرئيس الفرنسي فرانسوا ميتران : }
\end{aligned}
$$

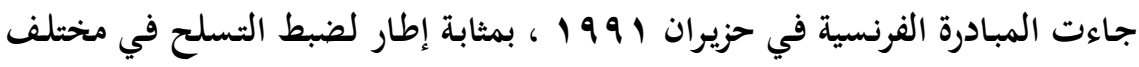

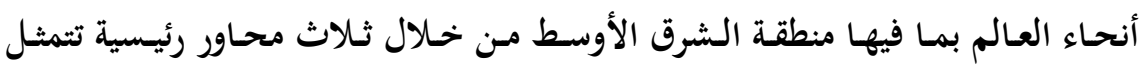

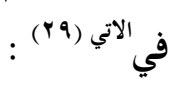

مقاصد نزع السلاح : وقد حددت الأهداف في القضاء على السلاح النووي

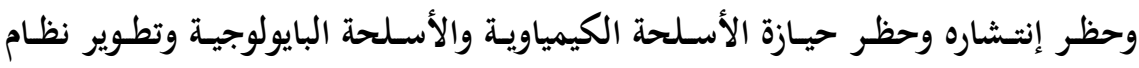

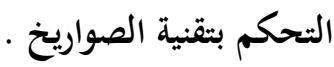

ب- على المستوى الأقليمي : تتضمن المبادرة تسوية النزاعات وإخلاء المنطقة

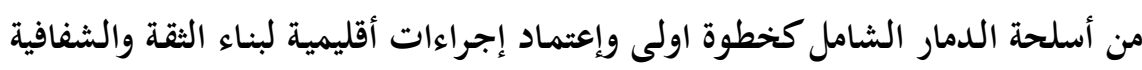
والثوصل الى توازن أقليمي فيما يتعلق بالأسلحة التقليدية .

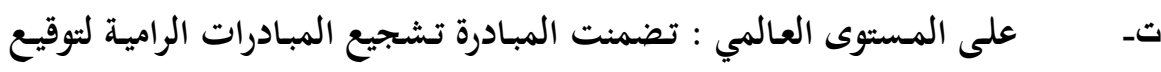

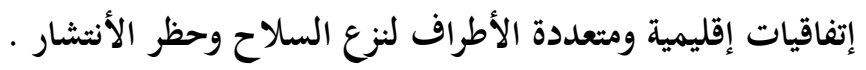

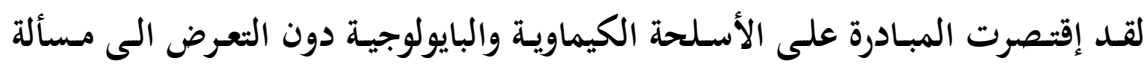

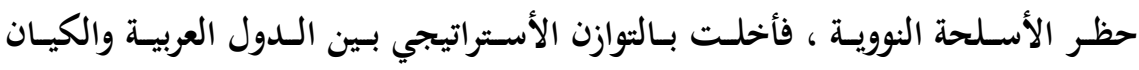

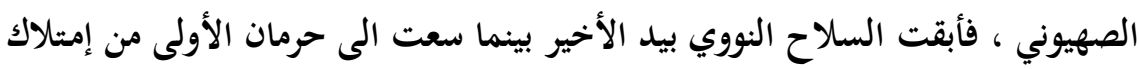

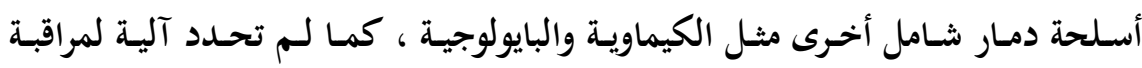

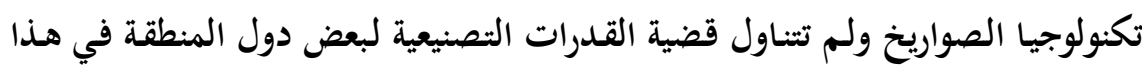

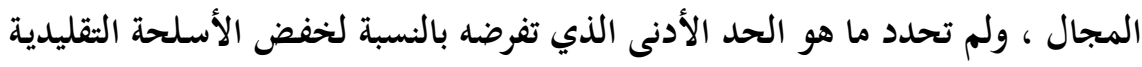

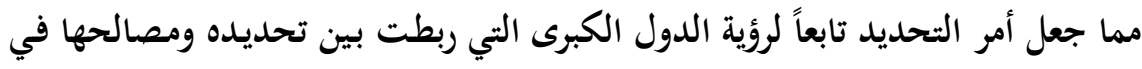

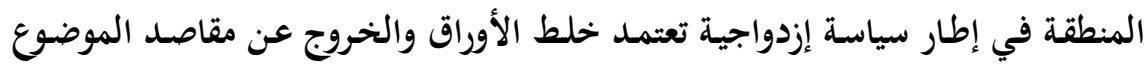


ثانيا: لجنة ظبط التسلح والأمن الأقليمي ( ACRSC ) : وهي واحدة من نتائج مؤتمر مدريد لعام 1991 ، ، حيث نوقشت مشكلة ضبط ضبط التسلح

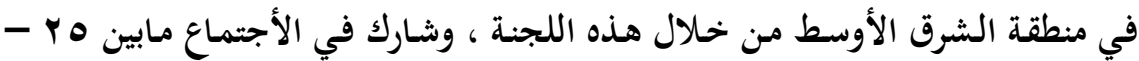

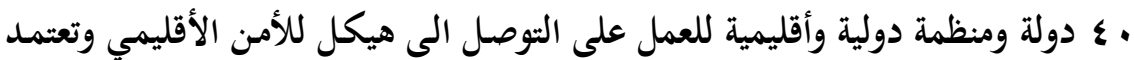
صيغة المعاهدات الثنائية ومتعددة الأطراف الى بناء الثقة والأمن من خحلال الضمانات

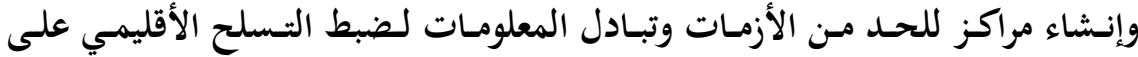

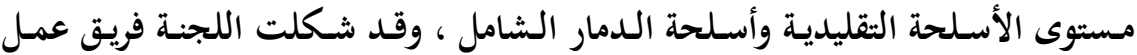

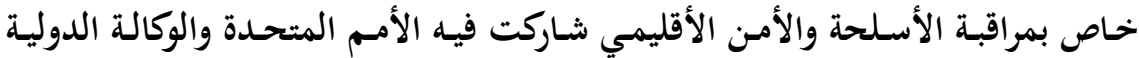
للطاقة الذرية وعقد هذا الفريق إجتماعـات دورية للفترة من ع 99 1 - ب9 99 1 ، ولم

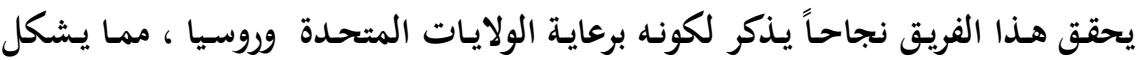

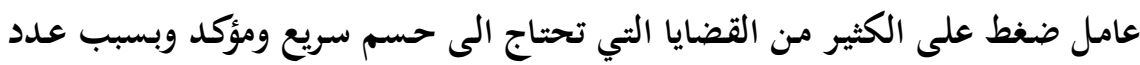

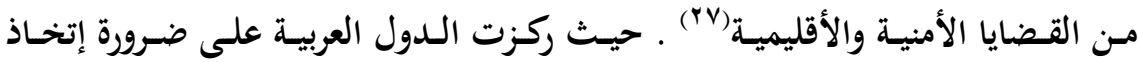

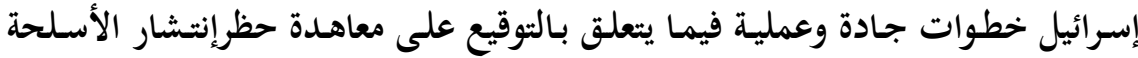

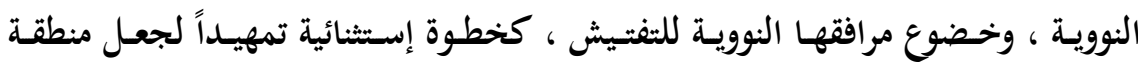
الشرق الأوسط منطقة خالية من أسلحة الدمار الشامل ، وبالمقابل رفضت إسرائيل

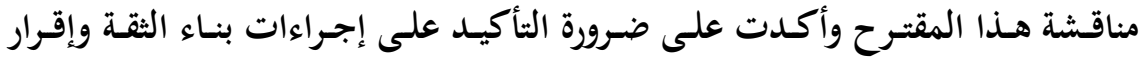

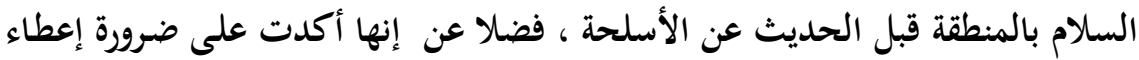

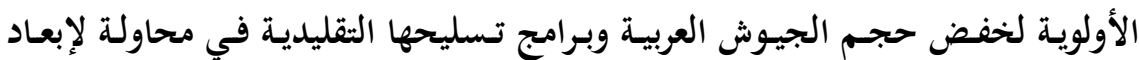

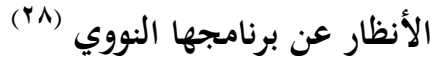
المحور الثالث: المبادرات الشرق أوسطية : تعد منطقة الشرق الأوسط من أكثر الأقاليم جدلاً وتعثراً في مجال إخلائها

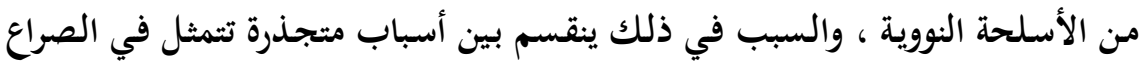

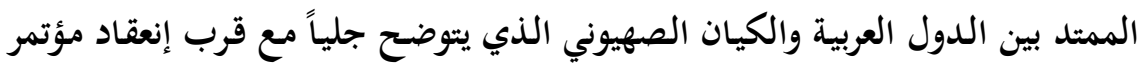

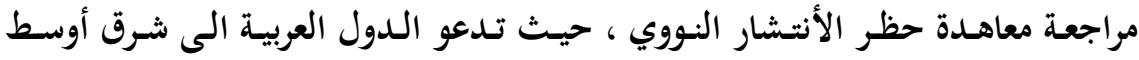




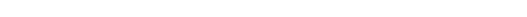

خالي من جميع أسلحة الدمار الشامل ، أو تدعو المجتمع الدولي الى تطبيق سياسات

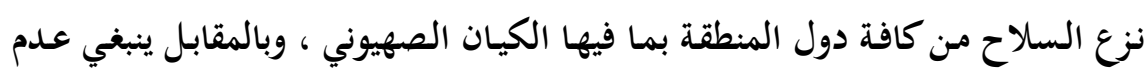

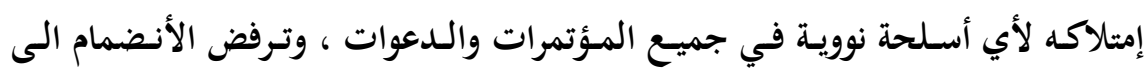

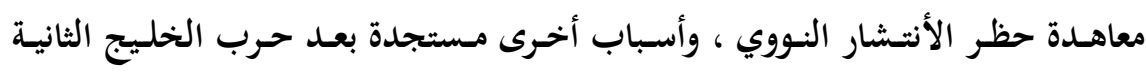

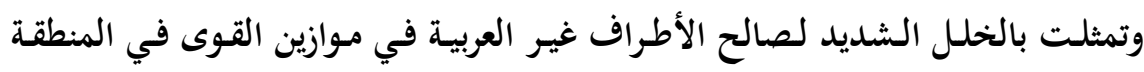

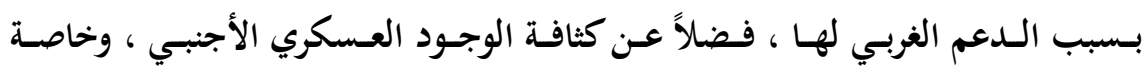

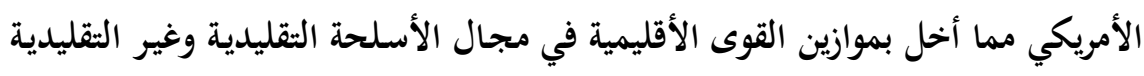

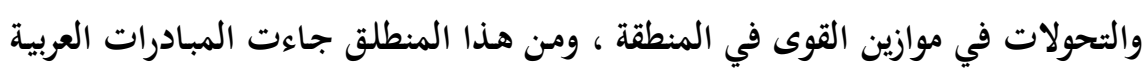

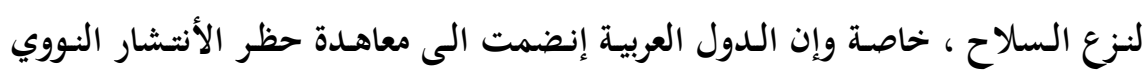

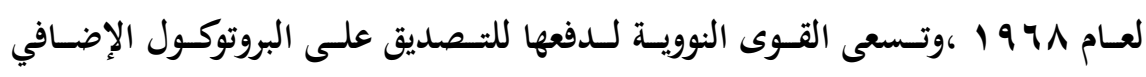

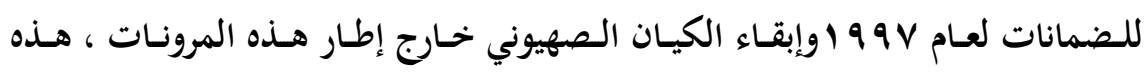

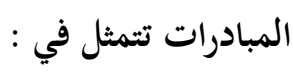

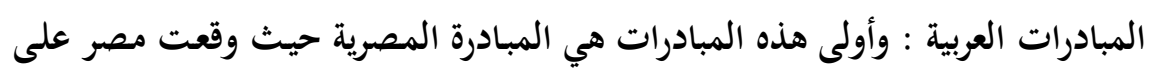

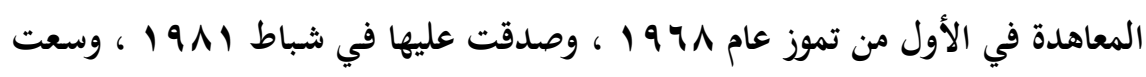

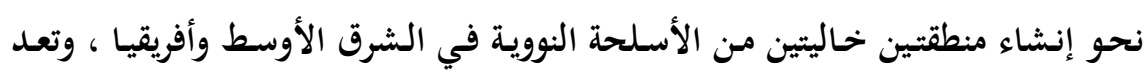

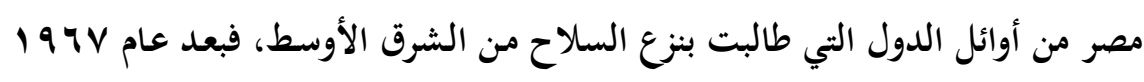

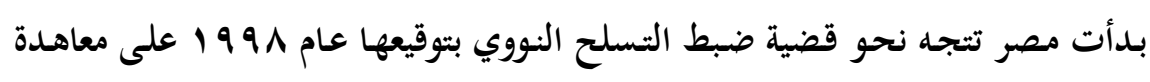

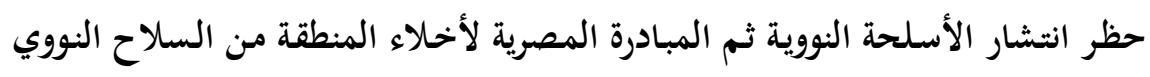

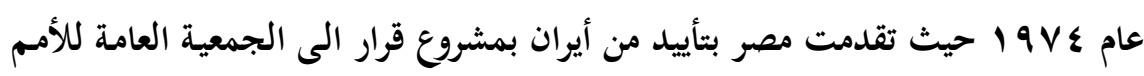

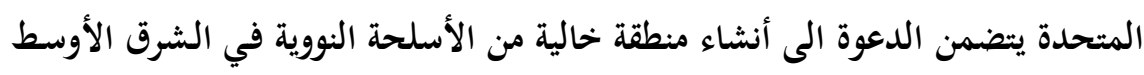

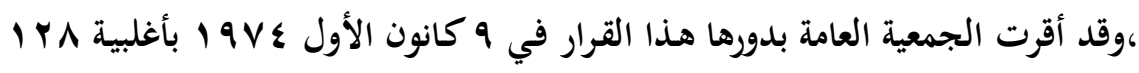

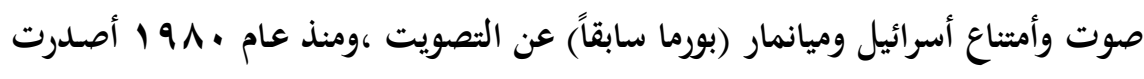

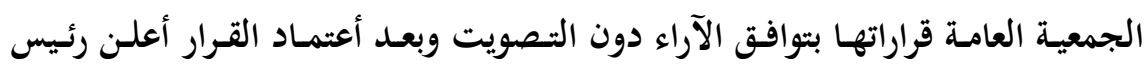

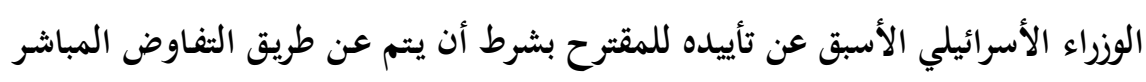


بـين دول المنطقـة وأقتـرح أقامـة منطقـة خاليـة مـن الأسـلحة الكيمياويـة في الـشرق (r.) الأوسط.

والدافع من وراء هذا الأندفاع المصري بأتجاه نزع السلاح يرتبط بالأحساس المتزايد بالخطر الصهيوني وتزايد هذا الهاجس او الشعور بالخطر في عهد الرئيس المصري

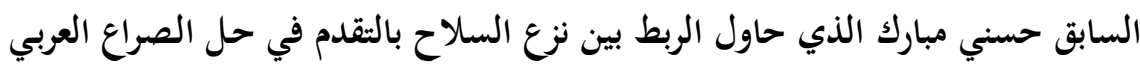

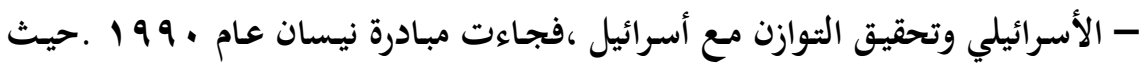

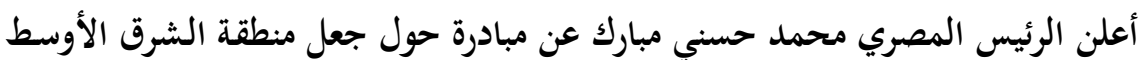

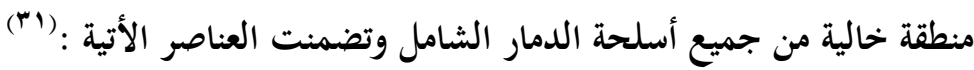
أ- عظر جميع أسلحة الدمار الشامل دون أستثناء .

ب- على جميع دول المنطقة بدون أستثناء تقديم ألنزامات متكافئة ومتبادلة .

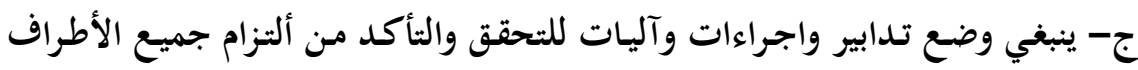
بالحظر.

وفي تموزعام 1999 | ،تقدم وزير الخارجيـة المصري عمـرو موسى بمقترحات أضسافية

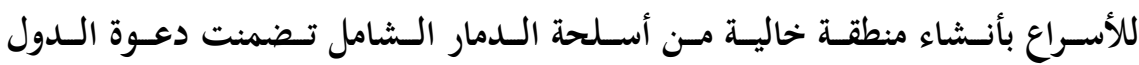
الرئيسة المصدرة للسلاح وخاصـة الـدول دائمسة العضوية إضـافة الى أسرائيل والـدول

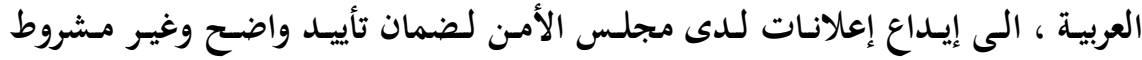

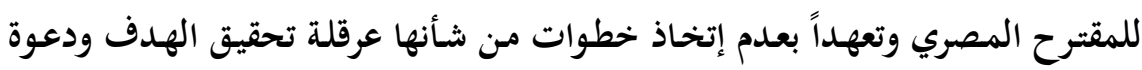

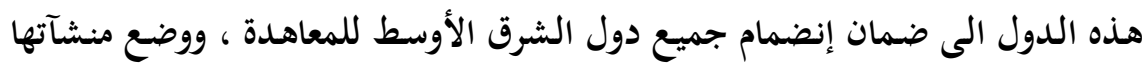

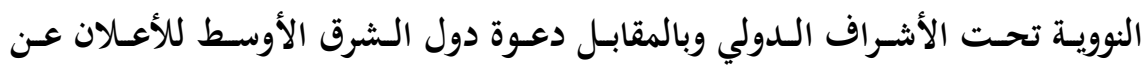

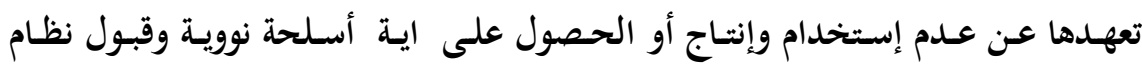

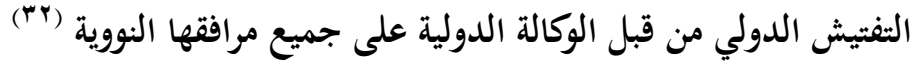

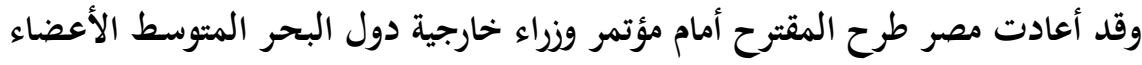
في حركة عدم الأنحياز، والذي عقد في مالطا ، وقد وافق أعضاء المؤتمر على المقترح

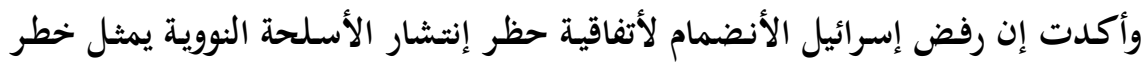

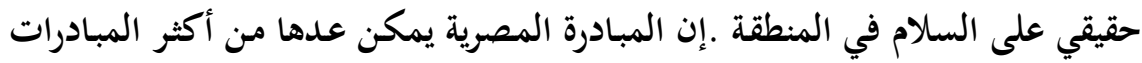


وضسوحاً وإصراراً في مجال نزع السلاح وإخحلاء منطقة الشرق الأوسط من الأسلحة النووية بهدف تحقيق النوازن في المنطقة وإحتواء المبادرات الدولية وخحاصة الأمريكية

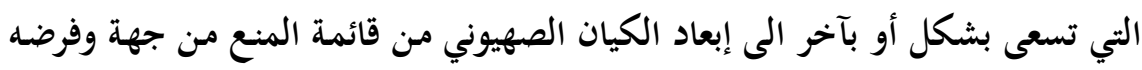
على الدول العربية من جهة أخرى للإبقاء على التفوق الأسرائيلي في المنطقة ، فمبادرة

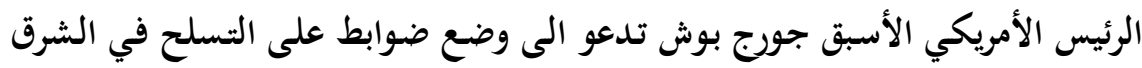

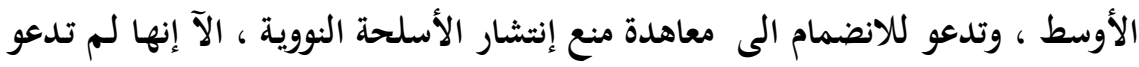
الى التخلص من مخزون الأسلحة النووية، وبذلك فقد ضمنت لإسرائيل الأحتفاظ بما

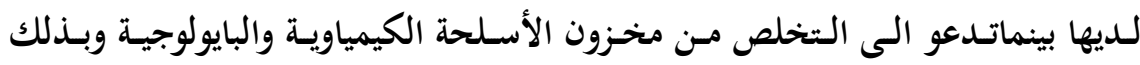

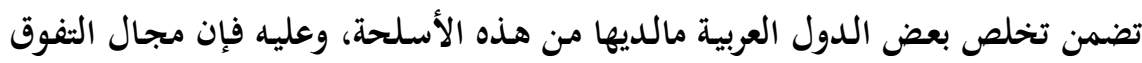

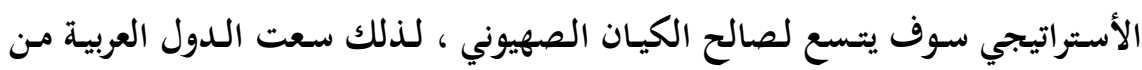
ضمنها مصر لتجاوز هذه الثغرة التي تسعى الدول الغربية الى الأبقاء عليها من خحلال

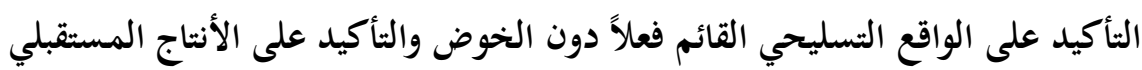

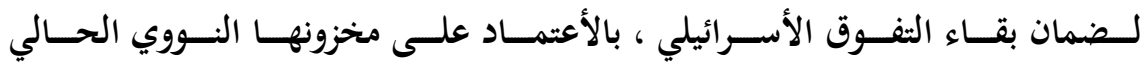

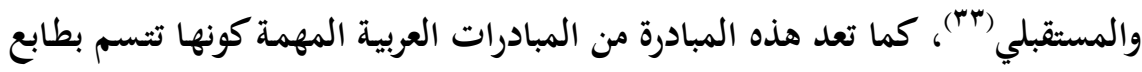
الشمولية بحيث تنظر الى دول المنطقة بشكل متساوي كما تدرس الوضع المعقد الذي

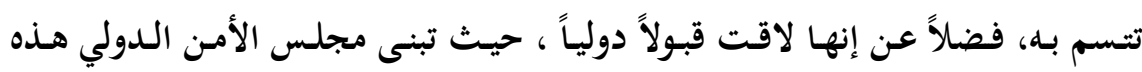

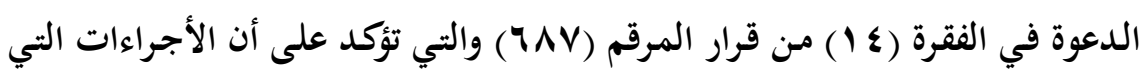

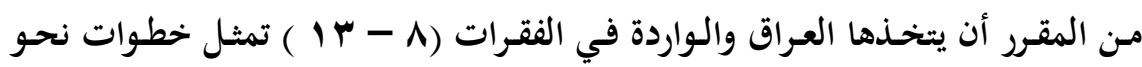

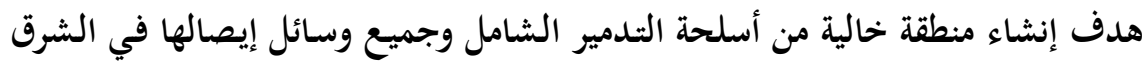
الاوسط وهدف فرض حظر عالي على الأسلحة الكيمياوية(؟َ" ) .

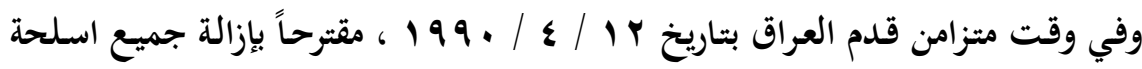
الدمار الشامل من منطقة الشرق الأوسط النووية والكيمياوية والبايولوجية الموجودة فعلاً

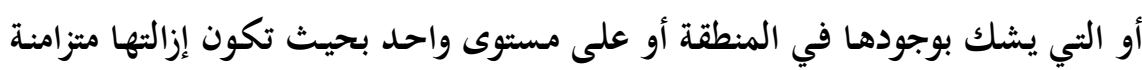

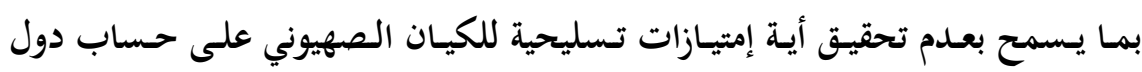

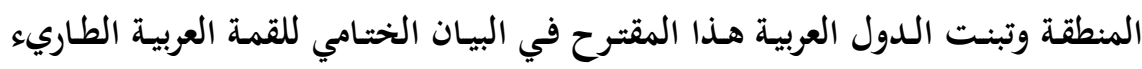


الذي عقد في بغداد في أيار عام • 199 ، الآ أن الولايات المتحة الأمريكية رفضت المسشروع العراقي وأبعـدت فكـرة الـربط بـين الأسـلحة الكيمياويـة والأسـلحة النوويـة الأسرائيلية ، خاصة وإن العراق إشترط في قيام منطقة منزوعة السلاح إنضمام إسرائيل

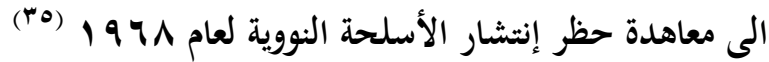
لقد ظهرت مبادرات عربية أخرى لاتخرج عن إطار المبادرة المصرية أو العراقية ، وربما

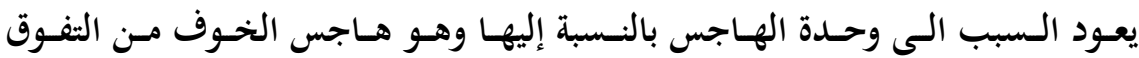

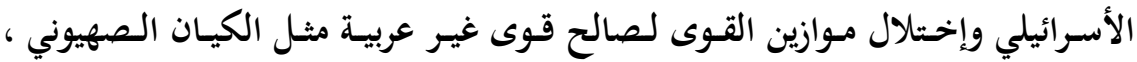

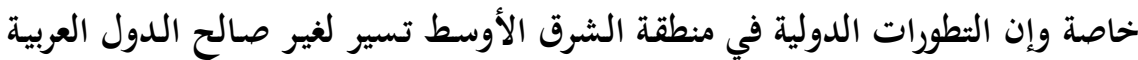
فالتواجد الأجنبي الكثيف بعد عام • 199 ، والتفوق العسكري لإسرائيل مقابل تراجع

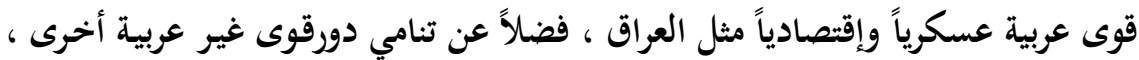

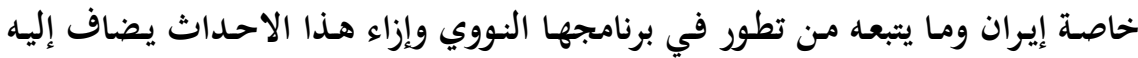

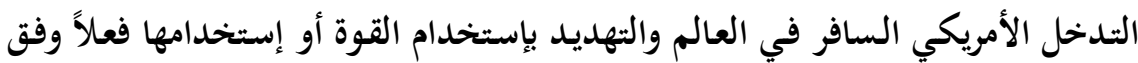
منطق الأنفراد والهيمنة دفع ببعض الدوي الدول الى تجنـب إشكالات العداء مـع الولايات

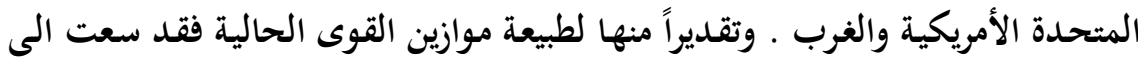

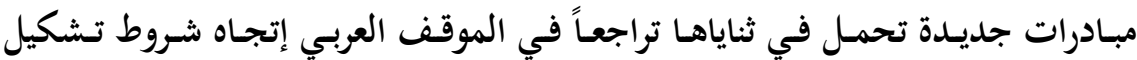
منطقة منزوعة السلاح في الشرق الأوسط ويتوضح ذلك في مبادرة الجماهيرية الليبية

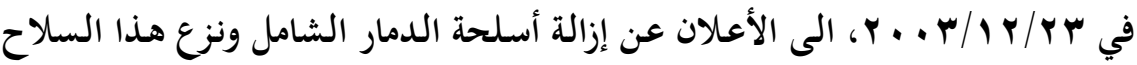
عـن بلـدها، وبينـت رغبتها للتوقيـع على البروتوكول الإضـافي الملحق لمعاهـدة حظر

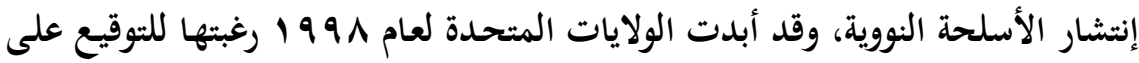

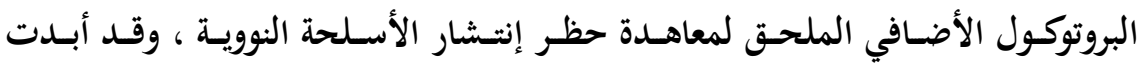
الولايات المتحدة الأمريكية هذه المبادرة وإعتبرتها خطوة مهمة للأقتداء بها من قبل المبل

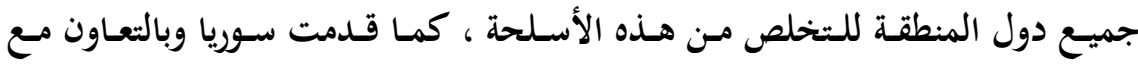

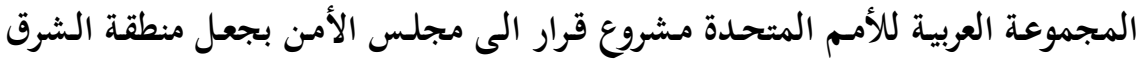

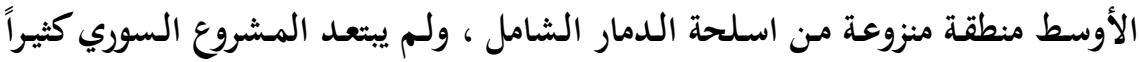


عن المشروع المصري الآ إنه مثل تراجعاً في الموقف السوري الذي يتمثل بالربط بين نزع أسلحة الكيان الصهيوني أولاً ، ثم البحث في منطقة منزوعة السلاح (بَ").

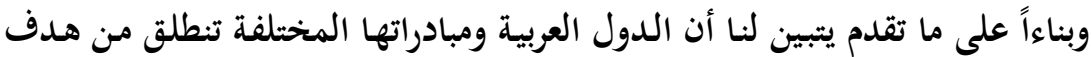

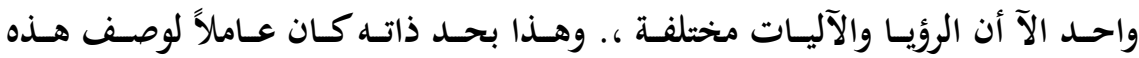
المبادرات كونها مبادرات ضعيفة وغير فعالة قياساً بالمبادرات والمشاريع الغربية ، هذا

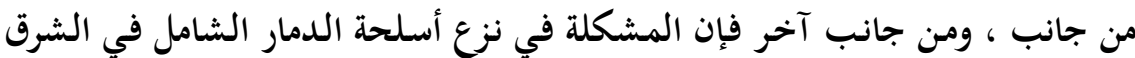

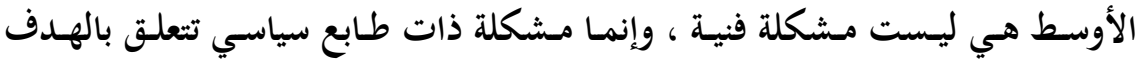

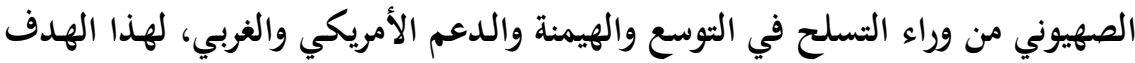
مقابل موقف عربي متشتت أو متفرق يسعى لغايات مختلفة رغم المصير الواحد .

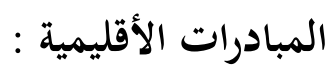

إن الدول العربية إنطلقت بمششاريعها لإنشاء منطقة منزوعة السلاح في الشرق

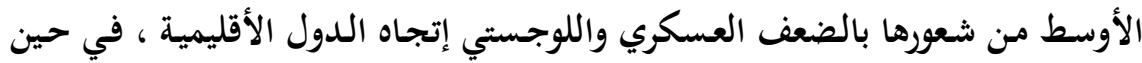
إن هذه الدول إنطلقت في مشاريعها لأهداف تتعلق بالحصول على على المكانة والقدرة على الردع بما يؤهلها قدرة سياسية تضمن لها دور دولي وأقليمي فعال ولذلك على إلى الرغم من التوافق في مشاريع هذه الدول مع المشاريع العربية من حيث الآليات الآ إنها

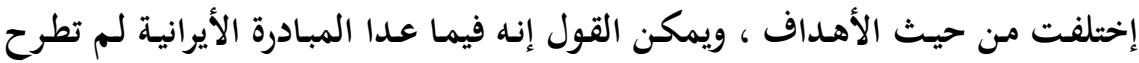
القوى الأقليمية الأخرى مثل تركيا أي مشاريع فعالة في مجال نزع السلاح في الشرق لهون

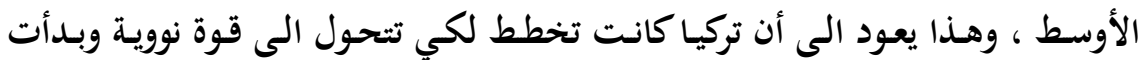

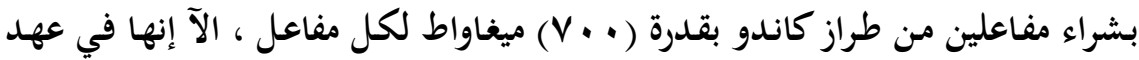
حزب العدالة والتنمية أعلنت رسمياً تخليها تلك الفكرة بإعلان رئيس الوزراء التركي

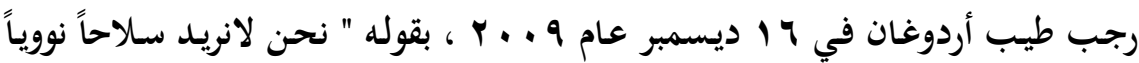

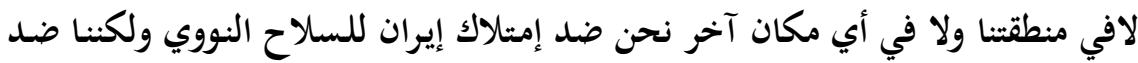

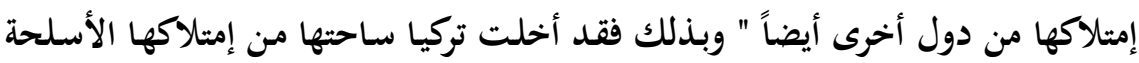


النووية ولكنها عوضت عن ذلك بإمتلاكها المظلة النووية الأطلسية وإتباعها دبلوماسية

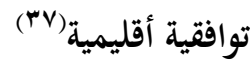
إن المبادرة التي تقدم بها شاه إيران الى الجمعية العامة للأمم المتحدة تعد من أولى الى

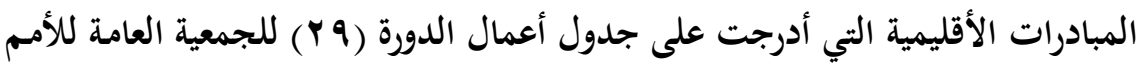

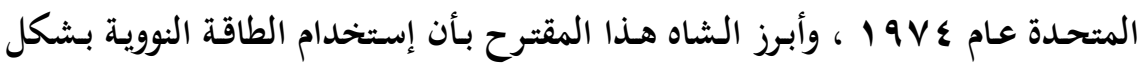

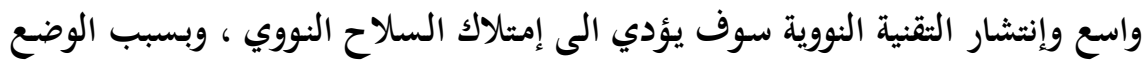
السياسي غير المستقر في الشرق الأوسط فإن ذلك سوف يدخل المنطقة في سباق من إنس الأسلحة النووية ، ويؤدي الى إستنفاذ الطاقات وتعريض المنطقة لكوارث التدمير لهذه

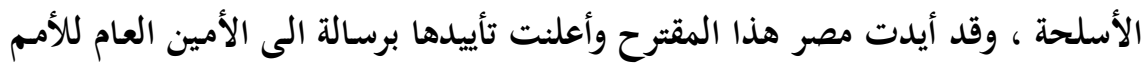

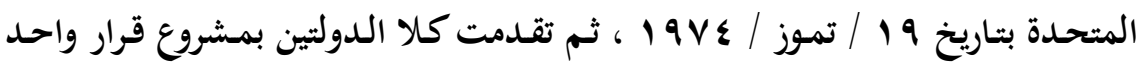

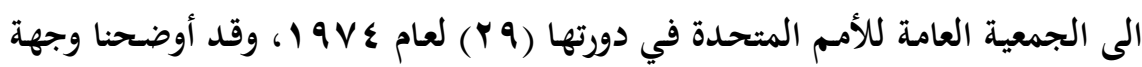

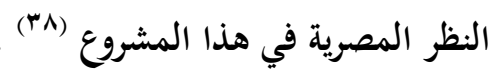
اما وجهة النظر الإيرانية فإنها لم تبتعد عن وجهة النظر المصرية الآ إنها كانت أقل

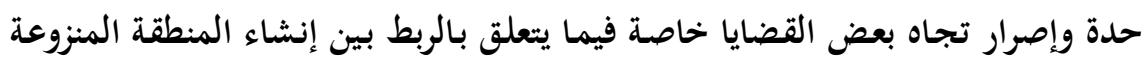

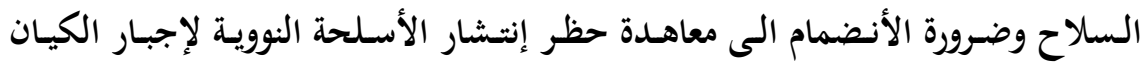

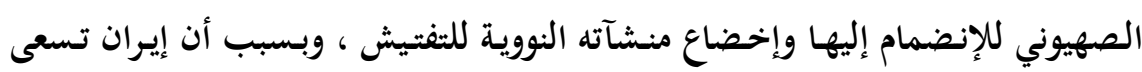

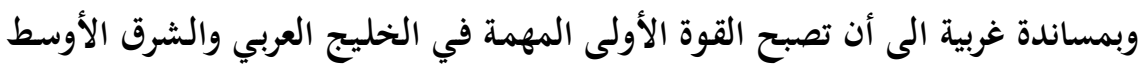

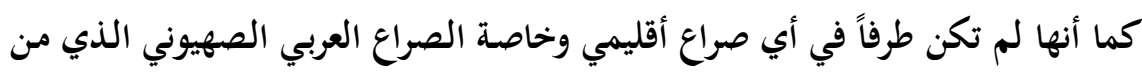

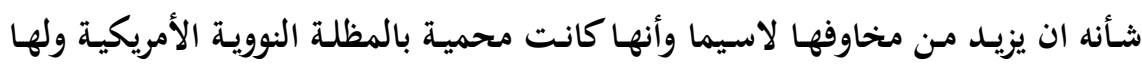

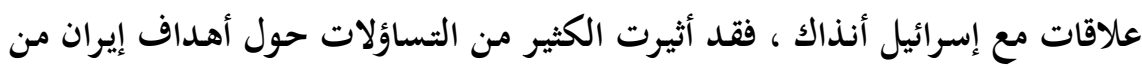

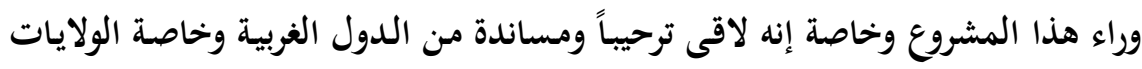

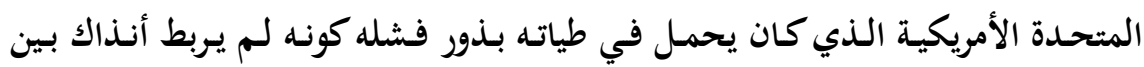

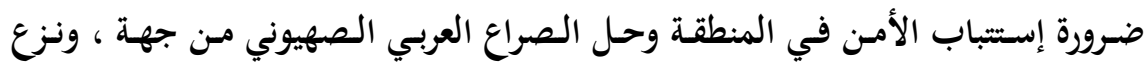

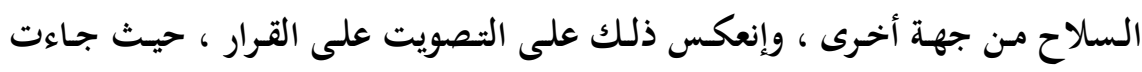

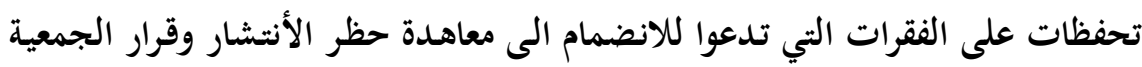




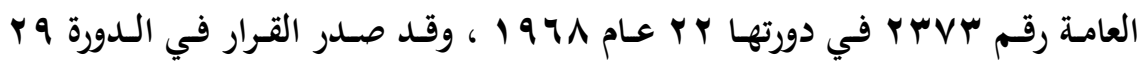

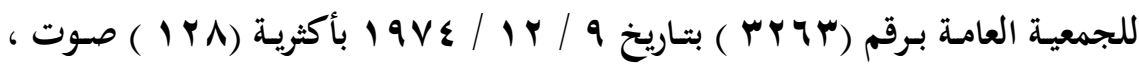

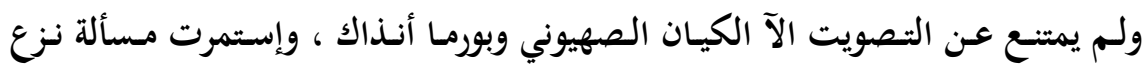

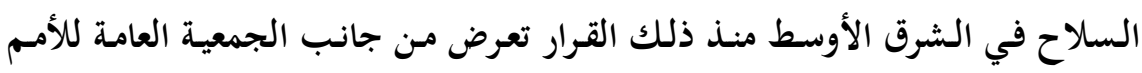

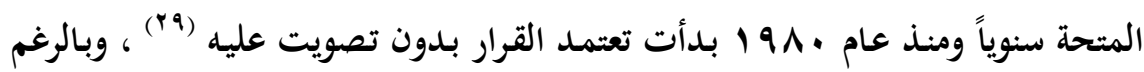

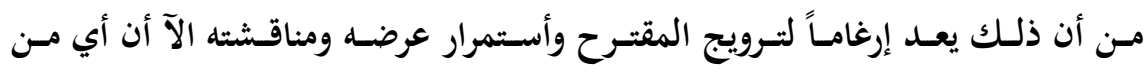

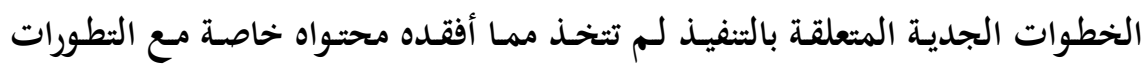

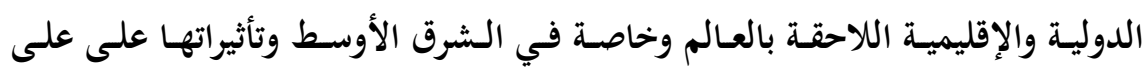

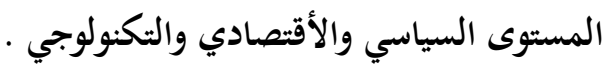

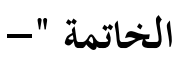

ان ازدواجيـة المعـايير في التعامـل الـدولي جعـل مـن هـذه المبـادرات مشاريع متجزئسة

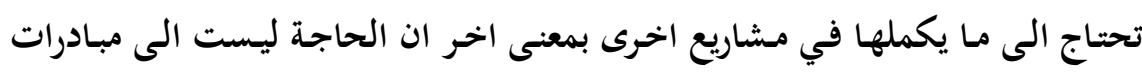

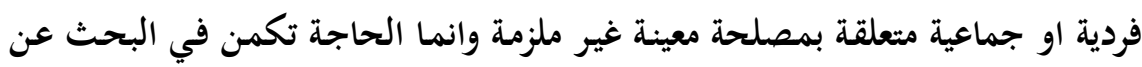

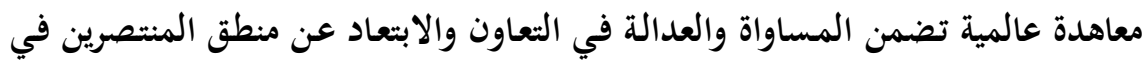

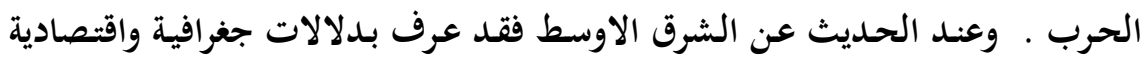

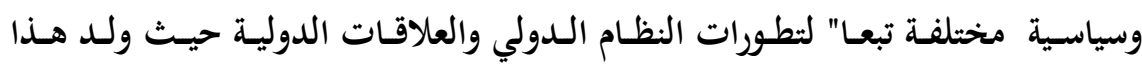
المصطلح بدلالة جغرافية عندما استخدم لأول مرة بمفهومه الجغرافي الجيوبوليتيكي

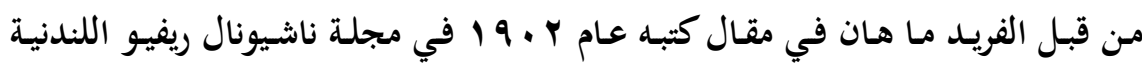
بعنوان الخليج الفارسي والعلاقات الدولية وقد اشار فيها الى المنطقة الواقعة بين الهند

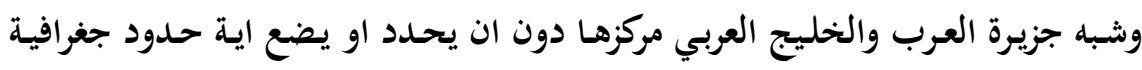
واضحة ومحـددة ، وبعـد الحرب العالمية الاولى عرف الشرق الاوسط بانه المنطقة

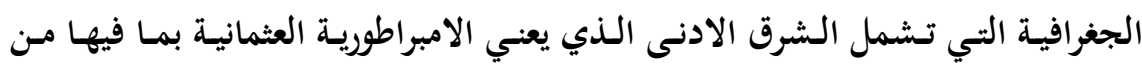

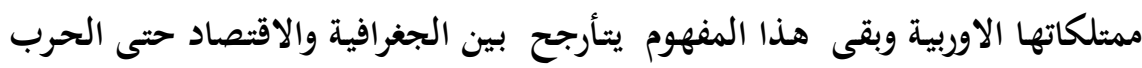

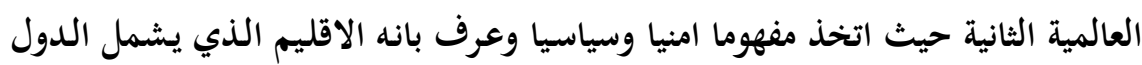


الممتدة من ايران الى مصر ومن تركيا الى اليمن وتبعا" لذلك فقد طرأت على تفاعلات الاقليم وعلاقاته الداخلية والدولية تغيرات وتطورات تركت اثرها على طبيعة النطورات العسكرية والامنية للمنطقة فالتغير الذي اصاب الوؤيا العسكرية الدولية من رؤى قائمة على حرب نووية شاملة الى رؤى تؤكد على القيمة العملياتية الفعلية لقوة التقليدية الى لى جانب القوه النووية وتامين قواعد متقدمة لانتشارها والذي افضى بالتالي الى مفهوم الانتشار المثقدم في اقاليم معينة في شرق اسيا واوربا والشرق الاوسط كل ذلك جعل

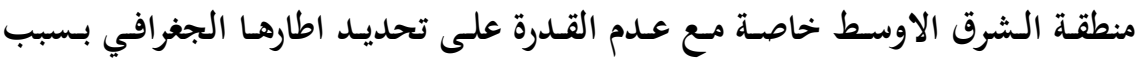
اختلاف المعايير المستخدمة او اختلاف غايات واهداف ومصالح كل طرف من هذا التحدي ترك اثره على قضية او اشكالية نزع السلاح وانشاء منطقة خالية من الاسلحة النووية في المنطقة حيث توضح عمق الصراعات والاختلافات في الاهداف والوسائل لـدول المنطقـة اضـافة الى عمـق التـدخلات الخارجيـة ودورهـا في صسيانة التفـاعلات والترتيبـات الامنيـة في المنطقـة ويظهر ذلك جليـا حتى على قـرارات الامـم المتحـدة

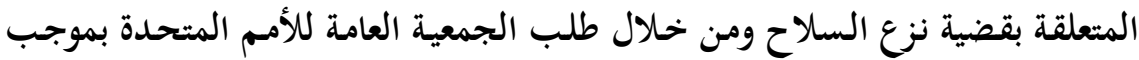

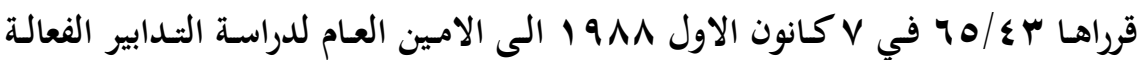

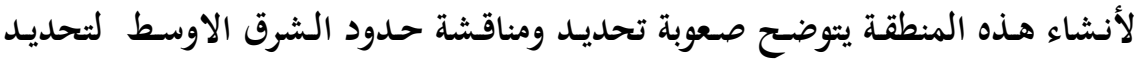

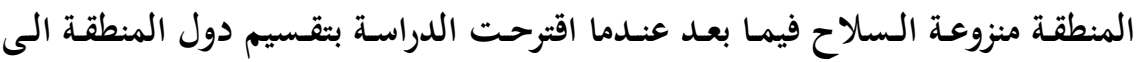
بلدان اساسيه و اخرى هامشيه مع الاخذ بالاعتبار الوضع الجغرافي والتوترات القائمة

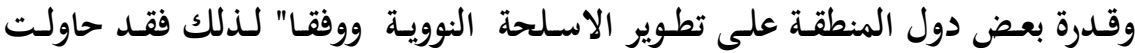
الوكالة الدولية للطاقة الذرية تعريف الشرق الاوسط بانه تلك المنطقة من ليبيا غربا" الى ايـران شـقا" ومـن سـوريا شـمالا" الى اليمن جنوبـا ، وهـذا التعريف يحـدد الدول الرئيسة والحد الادنى من الاطراف الضرورية لتحقيق المنطقة منزوعة السلاح وبسبب قصوره ضم فيما بعد جميع الدول الاعضاء في الجامعة العربية وايران واسرائيل الى

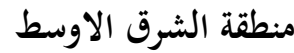
هذا الواقع الشرق اوسطي ترك اثره على مبادرات ومقترحات اخلاء الشرق الاوسط من الاسلحة النووية بحيـث اصطدمت بمعوقـات عديـدة حالت دون تطبيقها او تنفيذها 
على الرغم من اتساعها وتعددها ،وهذه المعوقات يتعلق بعضها بطبيعة الاقليم نفسه،

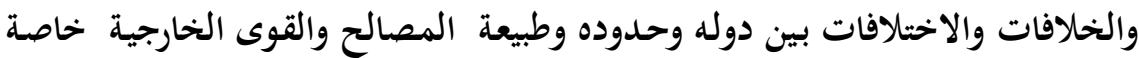
وان الاقليم يحتوي على ثروات نفطية ومعدنية وبشرية كبيرة فضلا" عن موقعه الجغرافي

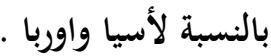
وبنـاءا"علسى مــا تقـدم فـسوف ننساقش اشـكالية نـزع الـسلاح في الـشرق الاوسط

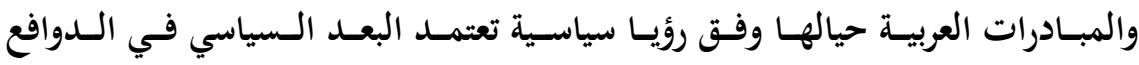
والمعوقات لقضية نزع السلاح وفقا" للاتي :1 - شهدت منطقة الشرق الاوسط مع بداية التسعينات مجموعة من التحولات الدوليسة والاقليميـة اثـرت علـى طبيعـة العلاقـات البينيـة والخارجيسة ، سـجلت خلـلا" واضحا" في ميزان العلاقات لصالح الاطراف غير العربية هي اسرائيل وايران وتركيا ،

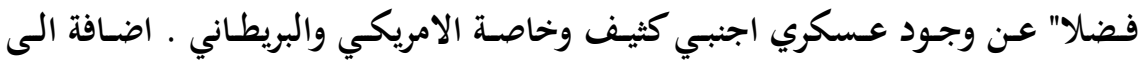

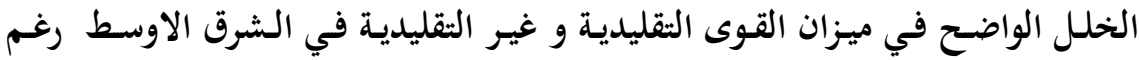

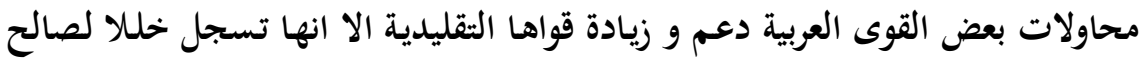
القوى غير العربيـة امـا القوى غير التقليدية فهي اولا مختلـه لصالح اسرائيل و ثانيا

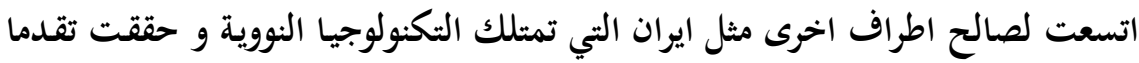
في مجال تخصيب اليورانيوم و توفير الوقود النووي لمحطاتها النووية ، في حين ان ان

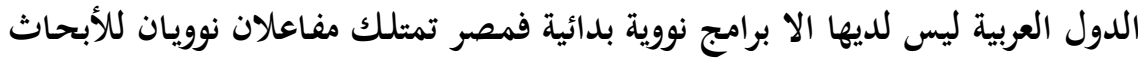

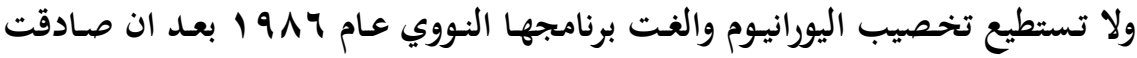
على معاهدة حظر الانتشار النووي عام 1911 .

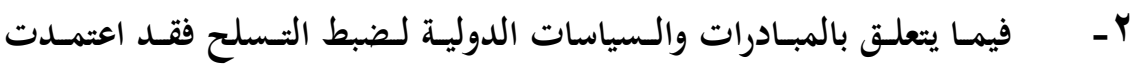

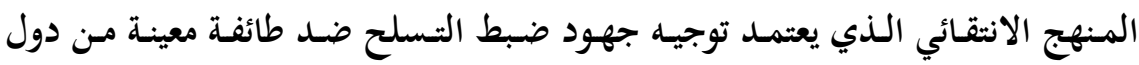

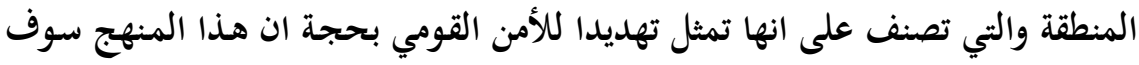

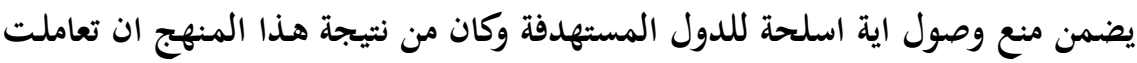

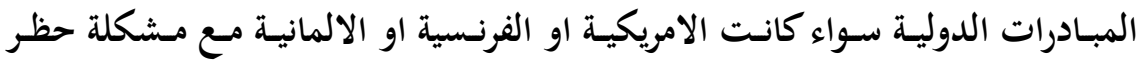

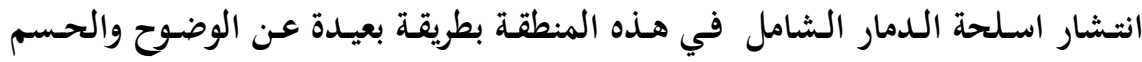


وبالرغم من ان جميع المبادرات لا تستنني اسرائيل من حظر السلاح النووي الا انها لا تذكرها صراحة كونها الوحيدة المشكوك بامتلاكها السلاح النووي كما انها تحاول ان

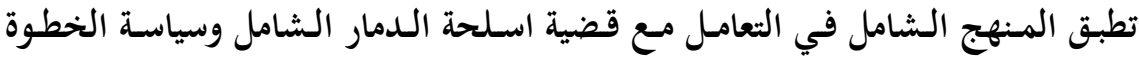
خطوة ، فهي تطرح مبـدأ التجميـد للإمكانـات الصاروخية ثم عمليـة نزع للصصواريخ

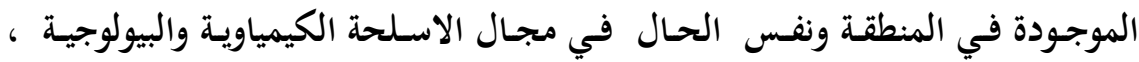
حيث ان مبادرة الرئيس الامريكي السابق جورج بوش تطرح مبدأ التجميد في المنطقة ،

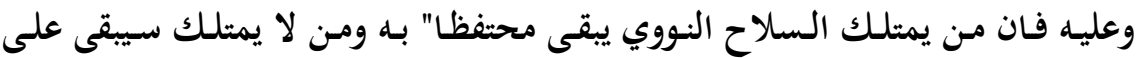
وضعه، فضلا" عن ذلك هناك خلل واضح في اليات وانظمة التطبيق والرقابة والتفتيش فلا يوجد مقياس دقيق لتحديد كميات الاسلحة ونوعيتها التي تسبب عدم الاستقرار ، ففي الوقت الذي تعطي الحق لدول المنطقة للاحتفاظ بقدرات صاروخية فهي لا تحدد

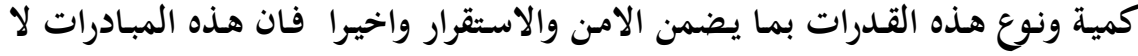
تنطابق مـع الثوجه والنفس العام لدول المنطقة ، فهي تتعامـل معها كأنها كل متكامل وليس دول مختلفة النظم السياسية والاقتصادية ومختلفة في الؤيا والاهداف .

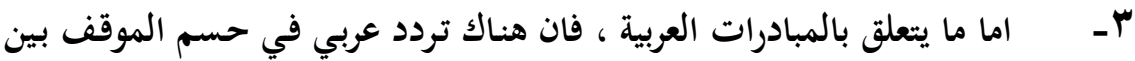

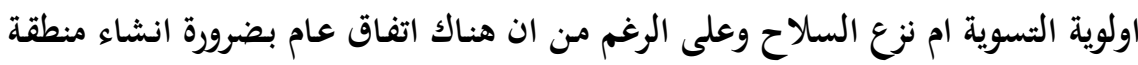

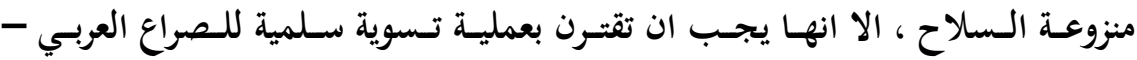
الصهيوني ، وبمـا ان هـذا السلام مس الصعب التوصـل اليهه خحاصـة مـع تعنـت الكيـان

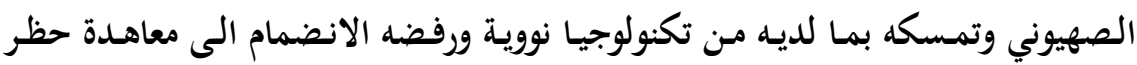
الانتشار النووي فان التوصل الى ترتيبات امنية تسليحية وخاصة ما يتعلق بأسلحة الدمار

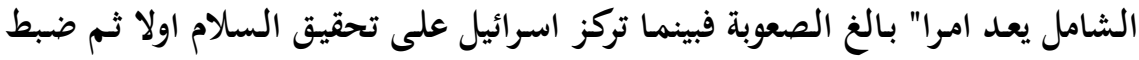

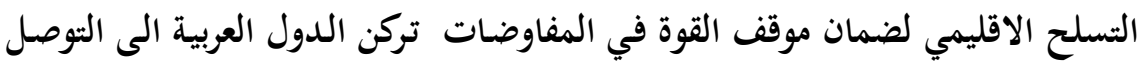

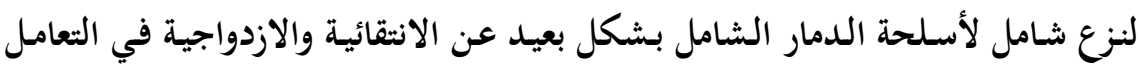

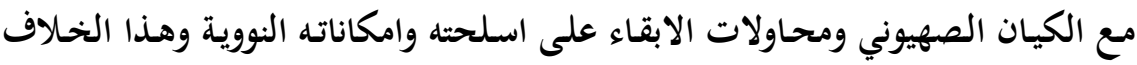
جعل المبادرات العربية تسير على النقيض من السياسة الاسرائيلية وتختلف في مجال

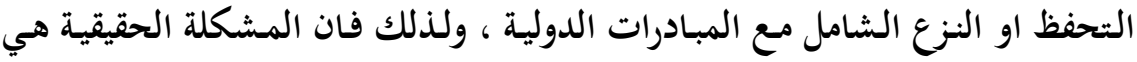


اشكالية نزع اسلحة الدمار الشامل في الشرق الاوسط تكمن ليس في اسباب قانونية او لوجستية او فنيسة وانمـا اسـباب تتعلق بـاختلاف التوجهات السياسية والطموحسات الامنية بين دول المنطقة، يضاف اليه انكشاف هذا الاقليم لحساب قوى غربية تسهم في تعميق هذه الخلافات من خلال اتباع سياسة انتقائية مزدوجة المعايير. واخيرا" لم يكن هناك تأكيدا صريحا على جعل منطقة الشرق الاوسط منطقة خالية من

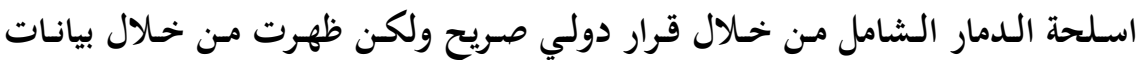
واضحة مثل المؤتمرات الاستعراضية الاخيرة لمعاهدة حظر انتشار الاسلحة النووية لعام

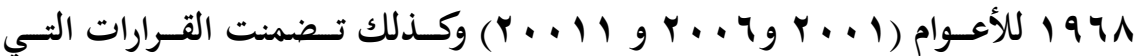
صـدرت ذات صـلة بـالقرارات التي سبقتها والمتعلقة بالأزمـة العراقيـة الكويتيـة وخاصـة

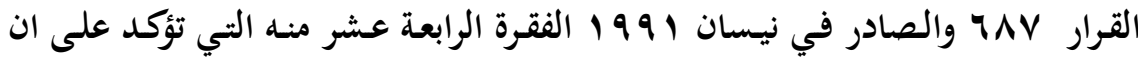
يعمل المجتمع الدولي من اجل العمل على جعل منطقة الشرق الاوسط منطقة خالية

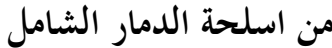

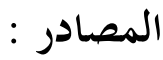

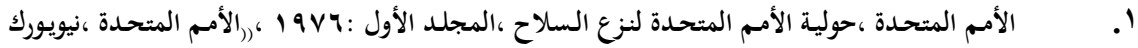

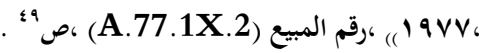

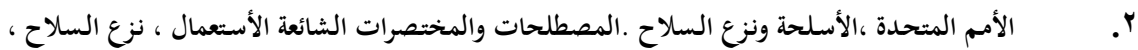

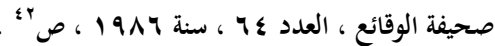

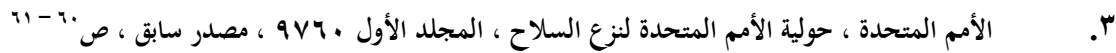
4. United Nations , Comprehensive study of the Question of nuclear - weapon - free zone in all its aspects, special report of the conference of the committee on disarmament , document : (A/10027/Add.1), Newyork, 1976, $\mathbf{p}^{48-49}$.

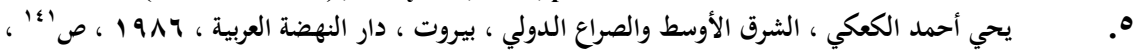

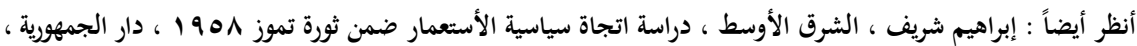

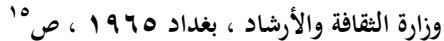
6. Arons Klionman, souviet Russia and midlle East, Jahns hophins press , London , $1970, p^{8}$.

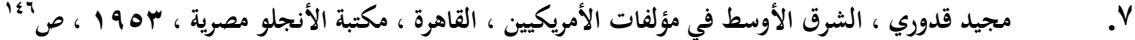

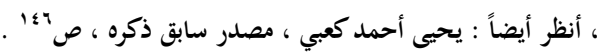

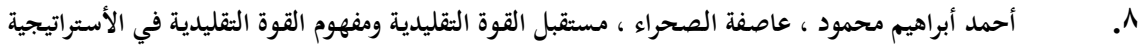

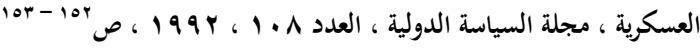


9 9. محمد عبد الرزاق شكارة ، الفكر الأستراتيجي الأمريكي والشرق الأوسط في النظام الدولي ، مجلة السياسة

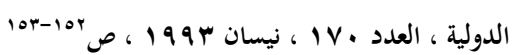

10. United Nations, General Assumly, Document, ( A/45 / 435 ), 10 October 1990 .

11. IAEA, Document, ( GC, XXX111 Y 887$), 29$ August, 1989, p $^{1-3}$.

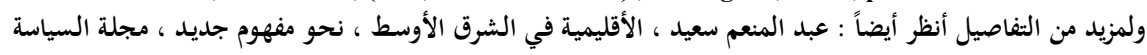

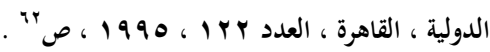

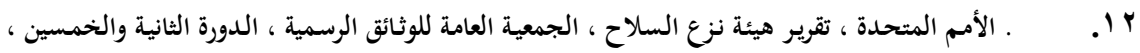

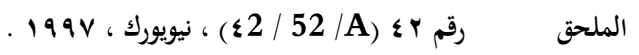

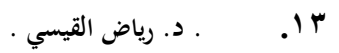

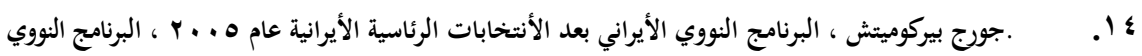

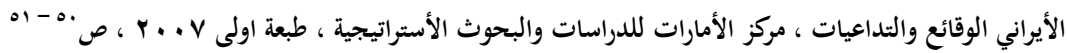

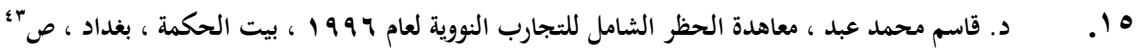

17 1. ممدوح حامد عطية ، إنشاء منطقة خحالية من أسلحة التدمير الشامل في منطقة الشرق الأوسط ، الخيار

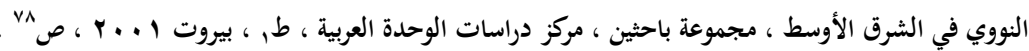

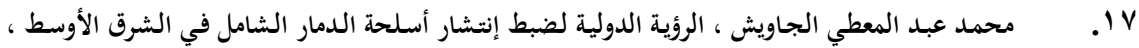

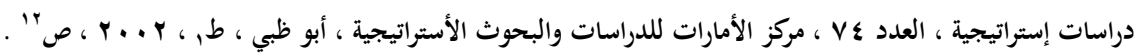

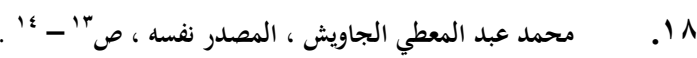

19. Public papers of the presidents, White House, fact sheet on the middle East- Arms control .Initidtive , Document , No . 688, 29 May 1991.

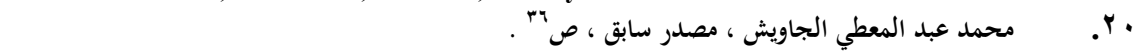

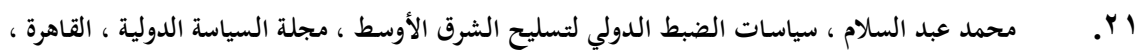

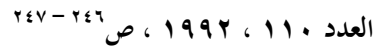

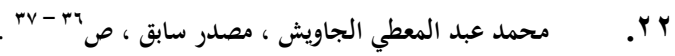

23. SIPRI, Year book, oxford University press, $1992, \mathbf{p}^{37-38}$.

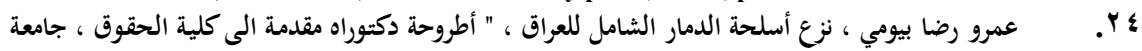

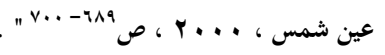

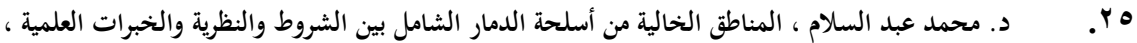

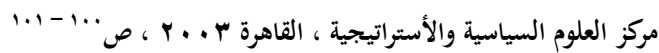

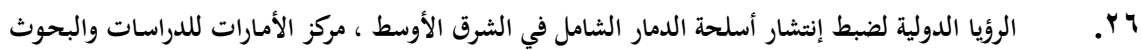

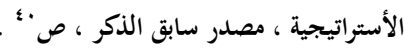

27. Michael D - Yaffe, promoting Arms control and Re qional secty in the middle East , Disarmament forum, UN, UNIDIR, NO:2, 2001 ,Geneva , p9 .

1 Y. محمد عبد المعطي الجاويش ، الرؤية الدولية لضبط إنتشار أسلحة الدمار الشامل في الشرق الأوسط ،

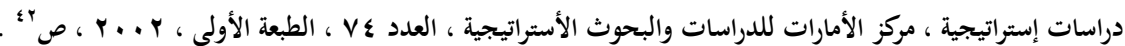

$$
\text { •rq }
$$




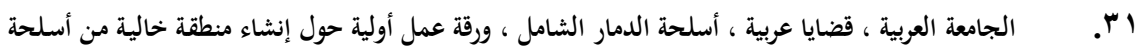

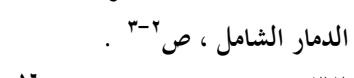

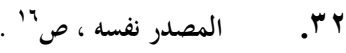

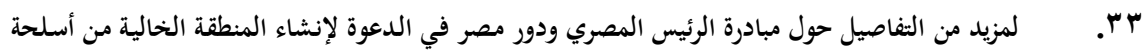

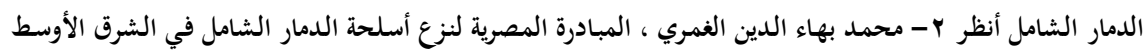

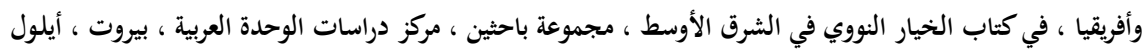

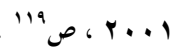

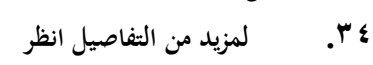

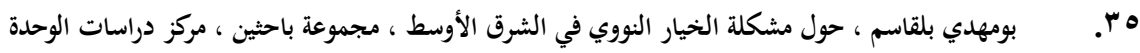

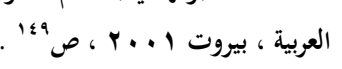

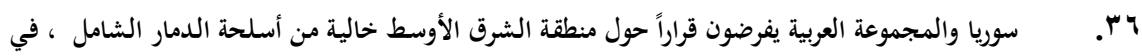

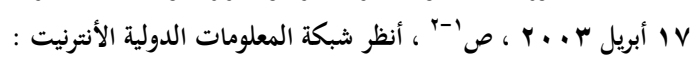

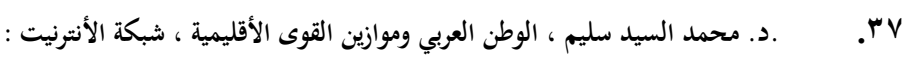

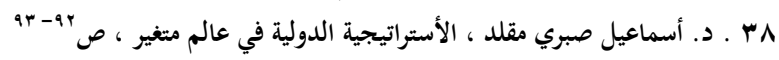

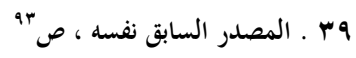

